\title{
Final Report 02-ERD-056 Active Load Control \& Mitigation Using Microtabs: A Wind Energy Application
}

D. Y. Nakafuji

February 24, 2003

U.S. Department of Energy

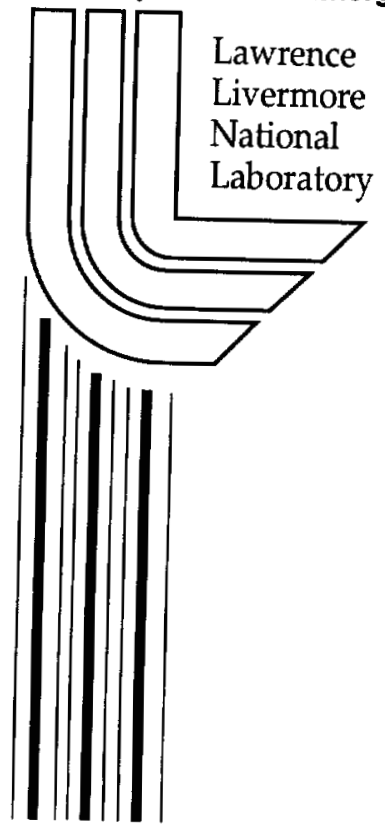




\section{DISCLAIMER}

This document was prepared as an account of work sponsored by an agency of the United States Government. Neither the United States Government nor the University of California nor any of their employees, makes any warranty, express or implied, or assumes any legal liability or responsibility for the accuracy, completeness, or usefulness of any information, apparatus, product, or process disclosed, or represents that its use would not infringe privately owned rights. Reference herein to any specific commercial product, process, or service by trade name, trademark, manufacturer, or otherwise, does not necessarily constitute or imply its endorsement, recommendation, or favoring by the United States Government or the University of California. The views and opinions of authors expressed herein do not necessarily state or reflect those of the United States Government or the University of California, and shall not be used for advertising or product endorsement purposes.

This work was performed under the auspices of the U.S. Department of Energy by the University of California, Lawrence Livermore National Laboratory under Contract No. W-7405-Eng-48.

This report has been reproduced directly from the best available copy.

Available electronically at http://www.doc.gov/bridge

Available for a processing fee to U.S. Department of Energy

And its contractors in paper from

U.S. Department of Energy

Office of Scientific and Technical Information

P.O. Box 62

Oak Ridge, TN 37831-0062

Telephone: (865) 576-8401

Facsimile: (865) 576-5728

E-mail: reports@adonis.osti.gov

Available for the sale to the public from

U.S. Department of Commerce

National Technical Information Service

5285 Port Royal Road

Springfield, VA 22161

Telephone: (800) 553-6847

Facsimile: (703) 605-6900

E-mail: orders@ntis.fedworld.gov

Online ordering: http://www.ntis.gov/ordering.htm

OR

Lawrence Livermore National Laboratory

Technical Information Department's Digital Library

http://www.llnl.gov/tid/Library.html 


\section{FINAL REPORT 02-ERD-056}

\section{Active Load Control \& Mitigation Using Microtabs: A Wind Energy Application}

UCRL-ID-XXXX

PI: Dora Yen Nakafuji 


\section{TABLE OF CONTENTS}

1.0 PURPOSE

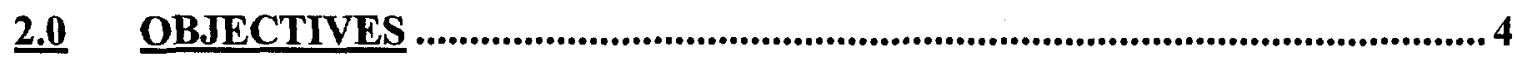

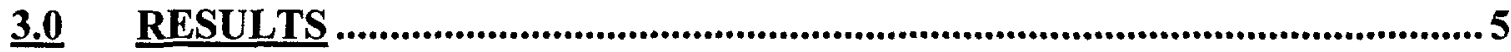

3.1 WIND TUNNEL UPGRADES \& TESTING [3,4] ................................ 5

3.1.1 Data Acquisition Hardware Upgrades ……....................................... 7

$\underline{3.1 .2} \quad$ Tunnel Wiring Upgrades.............................................................. 8

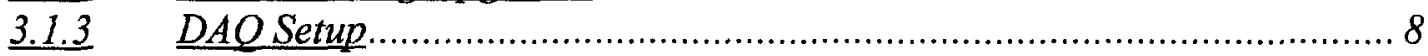

3.1.4 Resolution of the Traverse System..................................................... 11

3.1.5 Calibration of the Stepper Motors.................................................... 12

3.1.6 Flow Field Measurement Hardware Upgrades ...................................13

3.1.7 Tunnel Acquisition Interface Software Upgrades .................................. 14

3.1.8 Pressure Transducers \& Calibration .............................................. 15

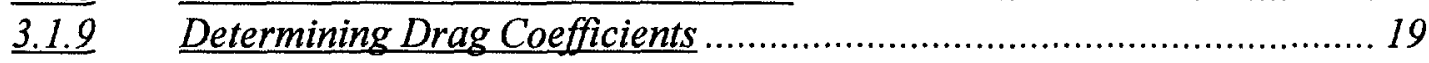

3.1.10 Experiment Validation Drag Results .................................................. 23

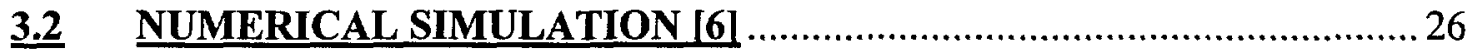

3.2.1 Grid Generator \& Numerical Solvers .................................................. 26

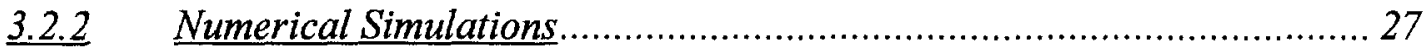

3.3 MICROTAB \& ACTUATOR DEVELOPMENT [24]..............................30

3.3.1 Actuator Design \& Development [26].............................................. 32

4.0 SUMMARY \& CONTINUING EFFORTS .................................................... 37

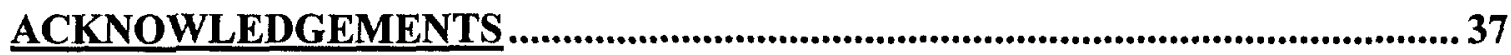

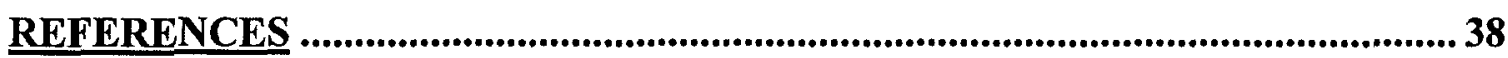




\subsection{PURPOSE}

With public concern over the security and reliability of our existing electricity infrastructure and the resurgence of wind energy, the wind industry offers an immediate, first point of entry for the application and demonstration of an active load control technology. An innovative microtab approach is being investigated and demonstrated for active aerodynamic load control applications under the mid-year LDRD (June-Sept. 2002) effort.

With many of these million dollar turbines failing at only half the design lifespans, conventional techniques for stiffening rotors, enlarging generators and gearboxes, and reinforcing towers are insufficient to accommodate the demands for bigger, taller and more powerful turbines. The DOE through the National Renewable Energy Laboratory (NREL) supports R\&D efforts to develop lighter, more efficient and longer lasting wind turbines and advance turbine components. However, as wind turbine systems continue to increase in size and complexity, fundamental research and technology development has not kept pace with needs. New technologies to increase turbine life spans and to reduce costs are needed to realize wind electricity generation potentials. It is becoming quite evident that without a better understanding of static and dynamic response to normal and abnormal operating loads coupled with sophisticated flow analysis and control techniques, large turbine operating life and component life will be severely limited. Promising technologies include active load control and load alleviation systems to mitigate peak loads from damaging key components. This project addresses science and engineering challenges of developing enabling technologies for active load control for turbine applications using an innovative, translational microtab approach. Figure 1.1 illustrates the microtabs as applied on a wind turbine system.

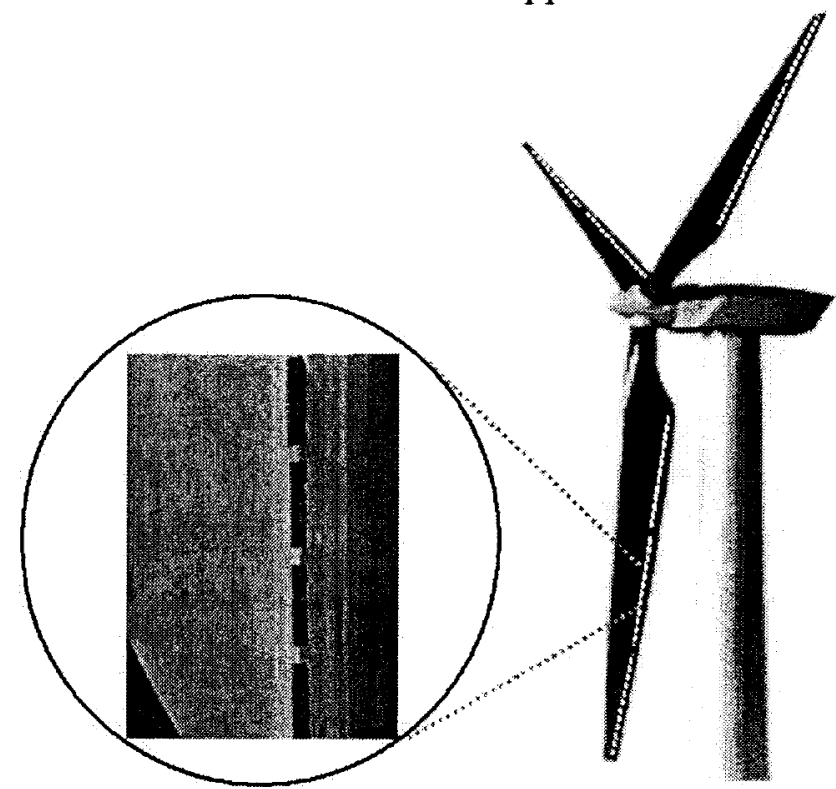

Figure 1.1 Microtab integration on wind turbine blades.

Extending wind turbine operating life is a crucial component for reducing the cost of wind-generated electricity, enabling wind energy market penetration and improving the reliability of the nation's renewable electrical generation infrastructure. This project 
also provides enabling technologies for improving turbine efficiency and durability to support the DOE and NNSA missions of providing energy security and reliability without contributing to greenhouse gas emissions and for decreasing dependence on foreign fuel sources.

In addition to wind generator applications, the realization of a "smart" controllable structure for load control using the microtab approach has the potential to revolutionize design of other complex systems. Driven by cost and safety, both passive and active flow control for steady and unsteady conditions have been actively investigated by NASA, DARPA, DOE and other research institutions for application on rotorcraft, UAVs, marine vessels and wind turbine applications. The potential to obtain revolutionary advances in aerodynamic/hydrodynamic performance, safety, maneuverability and service life by decreasing loads is an attractive prospect across many industries.

The microtab consists of a small tab that emerges from a lifting surface approximately perpendicular to its surface in the vicinity of its trailing edge (Figure 1.2). Tab deployment on the upper side of the lifting surface causes a decrease in the lift, whereas, deployment on the pressure side causes an increase.

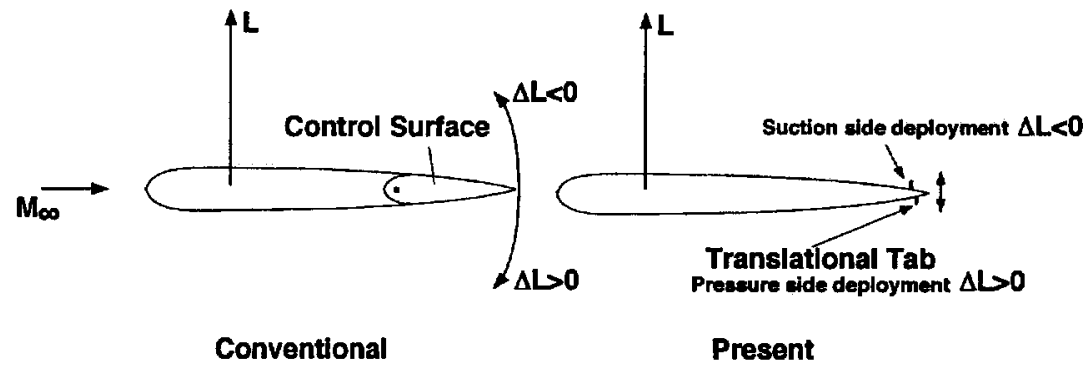

Figure 1.2. Sliding microtab control system vs. conventional rotating flap-type.

Through previous efforts [1,2], the PIs showed that the translational microtabs have demonstrated significant load control potential and may serve to reduce vibrations, bending and fatigue loads and even acoustic noise. To fully integrate the concept and study the impact to various industries, critical fluid modeling, actuator design and control and acoustic issues still need to be further developed and understood. The tasks performed under this mid-year project provide further knowledge and results to extended the concept. Major challenges for active load control include 1) Science: developing a deeper understanding of underlying steady and unsteady flow physics and structural interactions at the micro- and meso-scales 2) Engineering: designing and integrating robust, miniature actuators, sensors and controllers that can withstand macro-scale operating environments, and 3) Application: developing practical solutions to meet critical industry needs.

This report summarizes ongoing efforts by the primary research team from LLNL and UC Davis along with support staff from NASA, Sandia and NREL, to fully integrate the concept. The UC Davis team is comprised of graduate students (Jose Zayas, Michael Hopp, Candice Bauer, Kevin Standish, David Chao) under the guidance of Professor van Dam at UC Davis and Dr. Nakafuji at LLNL. The ultimate goal is to develop and establish a multi-year program to support research and eventual field test of the microtab concept in an active load control capacity. This report will focus only on current progress 
on experimental wind tunnel upgrades performed in order to conduct detailed microtab tests, 2-D to 3-D numerical simulation grids and actuator design efforts for the microtab concept. These efforts all support the goal of developing of a program for active load control technology and to pursue further funding opportunities.

\subsection{OBJECTIVES}

To achieve a synergy between the macro and micro design environments, a multidisciplinary, multi-year (2002-2004) approach is envisioned to focus on implementing the technology. Research plans are to use numerical simulations for flow analysis and design, experimental wind tunnel testing (at UC Davis) for validation and microfabrication technologies for design and optimization of the microtab actuator concept. The microtab design will utilize numerical simulations to assess the translational microtab concept for active flow and load control on lifting surfaces. The work will stretch existing fluid code capabilities to 2-D and 3-D flows in steady and unsteady analysis. Design of robust actuators for the microtabs will utilize a MicroElectro-Mechanical (MEMs) approach. To resolve many of the complex issues of design, control and integration, a multi-disciplinary team will be identified to focus on enhancing design techniques for microtabs and actuator integration. This approach also provides opportunities to strengthen ties with university collaborators, graduate students and other research agencies. The ultimate goal is to develop a program to support research and eventual field test of the microtab concept in an active load control capacity for either energy generation enhancements or aerodynamic performance applications.

The project scope under the mid-year LDRD only addresses part of the multi-year goals and begins to address some of the critical challenges identified in developing active load control capability using microtabs. The following tasks are planned under this project.

- Establish a collaborative team to further conduct experimental and numerical studies on the microtab;

- Conduct wind tunnel experimental sensitivity tests for wake-based wind tunnel measurements on a representative airfoil with upper surface and lower surface tabs to evaluate the effect of these tabs in controlling airfoil lift and drag characteristics on an airfoil. These data will be used to validate the CFD simulations;

- Use numerical models (2-D and 3-D) to support wind tunnel experiments and design trade-off studies;

- Develop a 3-D wake-based force analysis system to include hardware that will allow the evaluation of lifting surfaces with spanwise discontinues tab configurations;

- Plan acoustics testing of various microtab configurations;

- Design and develop a MEMs scale prototype actuator that meets the performance criteria for force and translational distance required using shape memory alloys or other potential actuation methods;

- Mentor and advise graduate students in the design, development and testing phase of project 
With successful completion of these phases of the project, LLNL will have developed a unique multi-disciplinary capability for designing and testing active load control using microtabs for energy applications as well as for aerodynamic applications. This will enable LLNL to offer and grow a capability that is essential but nonexistent in current wind energy research and development programs.

\subsection{RESULTS}

Under the mid-year efforts, numerous cooperative agreements were established to acquire equipment, software and gain access to facilities and staff. The research team was successful in completing many of the planned activities. Accomplishments to date include 1) establishing a cooperative agreement with the University of California, Davis to conduct microtab wind tunnel experiments. Funds provided support for 1) completion of numerous upgrades to the wind tunnel facility including hardware and software to enable detailed analysis; 2) completion of detailed drag studies and comparison to 2-D experimental results; 3) establishing collaboration with NASA Ames staff to provide support on Overflow, a 3-D RaNS code for numerical simulations; 4) implementing and generating working 3-D Chimera grids used for conducting simulations and design studies; 5) designing prototype actuation device; and 6) coordinating with NREL staff to conduct and complete acoustic testing of microtab geometries.

\subsection{WIND TUNNEL UPGRADES \& TESTING [3,4]}

The UC Davis wind tunnel is a low-speed open return tunnel (Figure 3.1.1). The test section has a length of $12 \mathrm{ft}$ and a rectangular cross section of $33.6 \mathrm{in} . \leftarrow 48 \mathrm{in}$. Typical test speeds are between $70 \mathrm{mph}$ and $150 \mathrm{mph}$, with a maximum tunnel velocity of $165 \mathrm{mph}$, empty tunnel. The honeycomb, anti-turbulence screen with a contraction ratio of 7.5:1 produces a turbulence intensity level below $0.1 \%$ within $80 \%$ of the test section. Additionally, the manufacturer predicts a flow angularity of less than \pm 0.2 degrees and a velocity variation of less than $\pm 0.75 \%$. A $125 \mathrm{hp} \mathrm{AC} \mathrm{motor} \mathrm{located} \mathrm{close} \mathrm{to} \mathrm{the} \mathrm{tunnel}$ outlet drives the fan. The chosen RPM -setting can be maintained within $\pm 0.2 \%$ of full scale (FS) by an electronic speed controller.

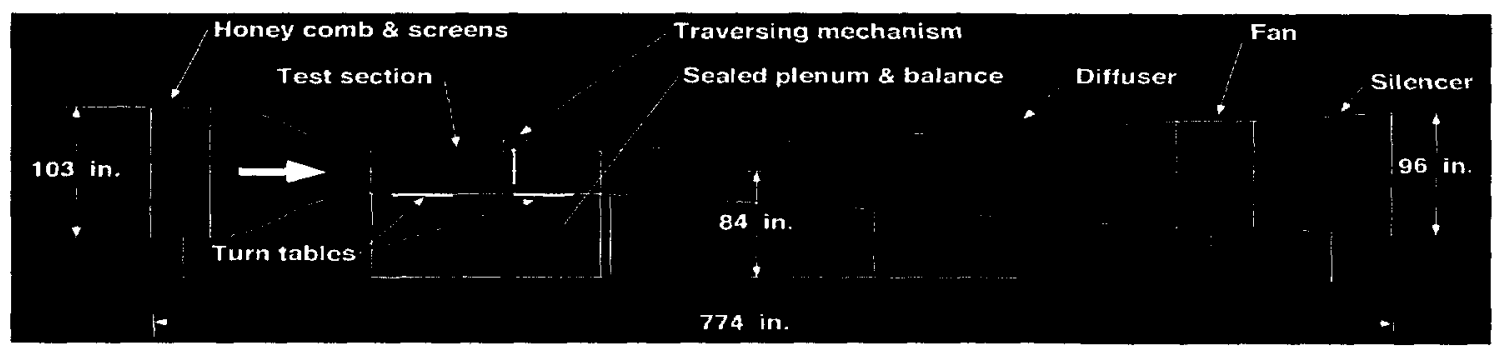

Figure 7. UC Davis low-turbulence subsonic wind tunnel.

Figure 3.1.1 UC Davis open return wind tunnel.

The tunnel is equipped with a pyramidal force balance installed below the turntable on which the model is mounted. Figure 3.1.2 shows the aerodynamic forces 
acting on the model such as lift (L), drag (D) and side-force (S), as well as the rolling$\left(M_{\text {roll }}\right)$, pitching- $\left(M_{\text {pitch }}\right)$ and yawing-moment ( $M_{\text {yow }}$ ) as captured by the interacting load cells of the balance. The angle $\psi$ represents the angle of attack for a vertically positioned winged section which can be adjusted by an electric motor.

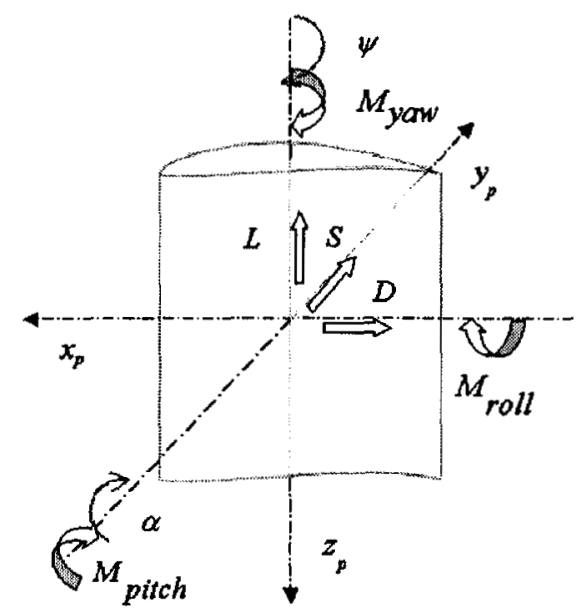

Figure 3.1.2: Forces and moments acting on the model.

The maximum rated load for each component is listed in Table 1 including a safety factor of $50 \%$. The accuracy of the balance given by the manufacturer is $0.1 \%$ of full scale based on each component loading.

Table 3.1: Maximum load limits for the force balance.

\begin{tabular}{|l|l|}
\hline Lift & $\pm 300 \mathrm{lb}$ \\
\hline Drag & $\pm 50 \mathrm{lb}$ \\
\hline Side Force & $\pm 150 \mathrm{lb}$ \\
\hline Pitching Moment & $\pm 70 \mathrm{ft}-\mathrm{lb}$ \\
\hline Rolling Moment & $\pm 50 \mathrm{ft}-\mathrm{lb}$ \\
\hline Yawing Moment & $\pm 50 \mathrm{ft}-\mathrm{lb}$ \\
\hline
\end{tabular}

The UC Davis wind tunnel is equipped with a traverse mechanism designed to move a probe vertically $(\mathrm{Z})$ or horizontally $(\mathrm{Y})$ across the test section of the tunnel. The traverse mechanism is installed on top of the tunnel test section (Figure 3.1.3). The entire mechanism can be moved to different stream wise (X) positions via the top slots. 


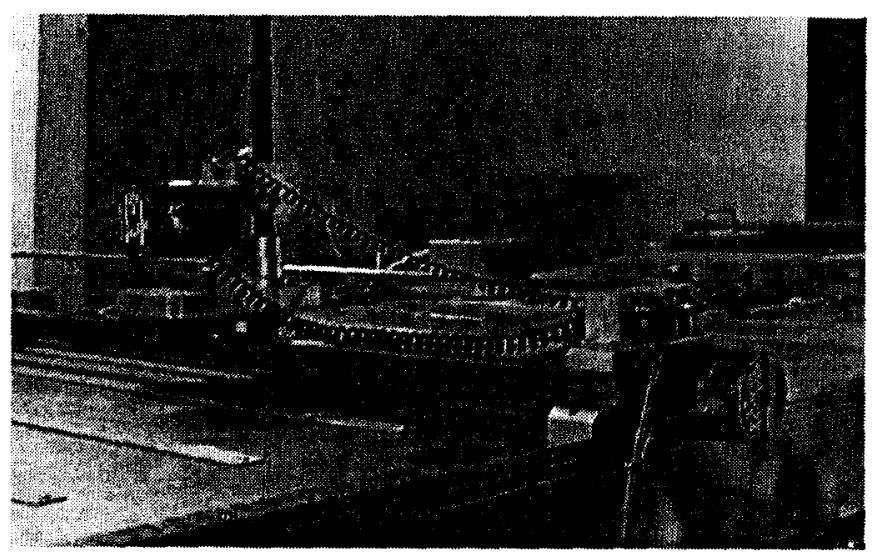

Figure 3.1.3. Traverse mechanism of the UCD wind tunnel.

Stepper drive motors are used to move the mechanism in the Y-and Z-axis. The cross support, which spans the top of the test section is a steel rail that carries a ball-bearing slider block manufactured by STAR. The load carrying capacity of the slider is in excess of 4000 pounds, providing strength and rigidity to the entire system. The slider block is moved transversely across the top of the tunnel by a lead screw and stepper motor. The vertical member is a thick-walled steel tube with a rack driven by a stepper motor and a planetary gear. The traverse mechanism tube is hollow in order for the pressure lines of the pitot static tube to exit the tunnel.

In this project, a method is developed to provide more precise control of positioning motors and to provide an option of automated control of motors using the data acquisition system. Numerous upgrades were made to the tunnel equipment and facility. The intention is to obtain a more effective wake analysis method that improves the experimental sampling time required to generate a dataset and leads to lower uncertainty levels in the overall results. Additionally, higher resolution and control of the equipment lead to more precise wake profiles and improves the quality of the calculated force coefficients.

\subsubsection{Data Acquisition Hardware Upgrades}

PC:

- Dell Optiplex (1.13 GHz Pentium 3)

- $256 \mathrm{Mb}$ of Ram

- $20 \mathrm{~Gb}$ Hard Drive

- Windows 98

Software:

- National Instrument ${ }^{\mathrm{TM}}$ (NI)

- LabVIEW'TM $6 \mathrm{i}$

- $\quad$ NI ${ }^{\mathrm{TM}} \mathrm{DAQ}$

- Microsoft $^{\circledR}$ Office 97

- Word 


\section{- Excel (Data post-processing)}

Data Acquisition Hardware:

- National Instrument ${ }^{\mathrm{TM}}$ PCI-6071E Multi-purpose DAQ card

- $1.25 \mathrm{MS} / \mathrm{s}, 12$-bit resolution, up to 64 analog inputs

- Two 12-bit analog outputs (1 MS/s max)

- 8 digital I/0 lines (5 V/TTL); two 24-bit counter/timers

- Analog and digital triggering

\subsubsection{Tunnel Wiring Upgrades}

Through previous experiments in the tunnel facility [5], significant electromagnetic fields (EMF) were observed. To protect against noise spikes and electromagnetic interference in the facility, new cables and shielded equipment was acquired and utilized. A NI SCB-100 shielded I/O connector block is used for interfacing I/O signals to plug-in the DAQ device with a 100 pin connector (Figure 3.1.4). It includes a temperature sensor for thermocouple cold-junction compensation and a general-purpose breadboard area. The screw terminals and the breadboard areas are housed in a metal enclosure to shield the connector block from EMF. A NI SH100100 shielded cable connects the connector block to the DAQ device. It is terminated with 100-pin 0.050 series D-type connectors and has a total length of $2 \mathrm{~m}$.

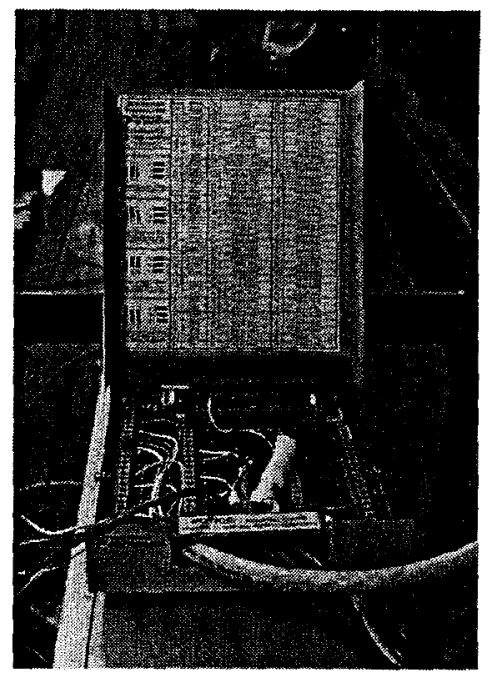

Figure 3.1.4. Shielded connector block

\subsubsection{DAQ Setup}

The new data acquisition device leads to the availability of up to 32 differential input and eight digital output channels. This opens the possibility of recording all readings and controlling all components of the wind tunnel facility with the DAQ computer. For this purpose the wiring of the facility has been rearranged. Figure 3.1.4 introduces the new data acquisition setup. 


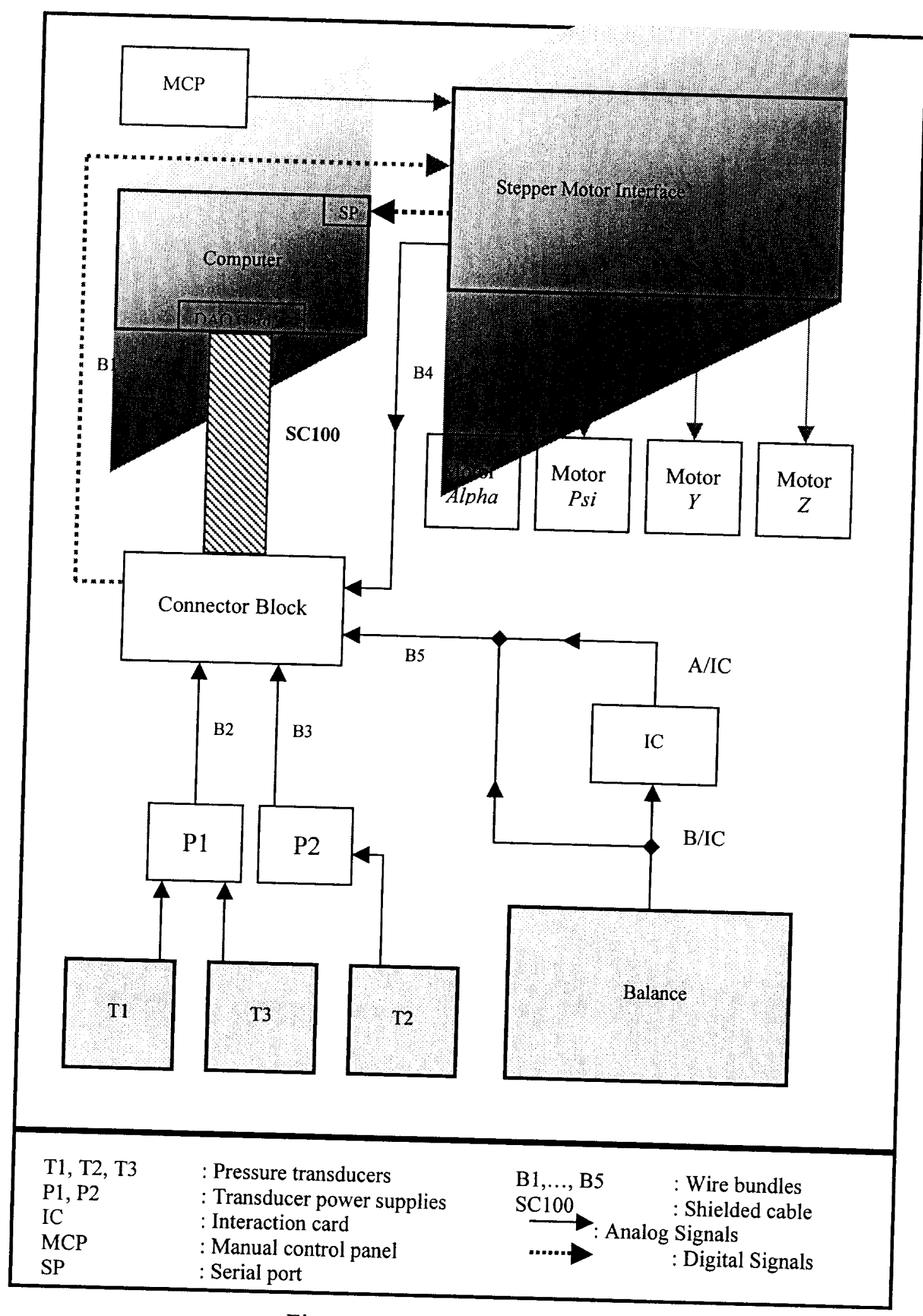

Figure 3.1.4. Data acquisition setup. 
The 6 single ended force and moment voltages generated by the balance are within a range of $\pm 3 \mathrm{~V}$. An interaction card (IC) that is supposed to correct for the interactions of the different balance components produces 6 additional single ended voltages. Therefore, the readings that come directly from the balance are labeled with B/IC (before interaction card) and the readings that come from the interaction card are labeled with $\mathrm{A} / \mathrm{IC}$ (after interaction card). Bundle $\mathrm{B5}$ summarizes all wires coming from the balance $(\mathrm{A} / \mathrm{IC}$ and $\mathrm{B} / \mathrm{IC}$ ) and plugs into the connector block.

The pressure transducers $\mathrm{T} 1$ and $\mathrm{T} 3$ are powered by power supply $\mathbf{P 1}$. The use of the third transducer $\mathrm{T} 2$ requires an additional power supply $\mathbf{P 2}$. Both power supplies provide 24 VDC. The wires of transducers T1 and T3 are summarized in bundle B2, while the wires of $\mathrm{T} 2$ are labeled with B3. All transducers provide differential voltages between zero and five VDC. The step position of each motor is read in digital form with the serial port SP of the data acquisition computer using a 12-bit signal leading to a number of 4096 possible steps for each motor. For this purpose an electrical circuit designed by Nelson Smith, which generates a precise binary reading related to every motor step, has been integrated in the motor interface system. A circuit schematic of this motor position sensor is shown in Appendix D. Additionally, this circuit provides a single ended voltage reading for every motor, which is equal to the respective digital step position divided by 1000. These analog signals are led to the connector block through bundle B4. The digital output from the connector block used to select the different motors, to control the motor speed and state (running or not running) is connected to the motor interface through bundle B1.

The shielded cable SC100 leads all signals from the connector block to the data acquisition card of the computer. Table 3.2 shows in detail to which data acquisition pin of the connector block every wire is related and the assigned channel of the DAQ card. Furthermore, it contains the information if the signal is of the single ended (SE), the differential (diff) or the binary type, whether it is an input (I) or an output (O) signal and it shows the way in which the wires are summarized in the different bundles. The numbers in parenthesis in the "wire" column indicate to which pin of the bundle plug a wire is related (only applied to bundles with multiple wires). 
Table 3.2. Wiring schematic of the new data acquisition system

\begin{tabular}{|c|c|c|c|c|c|c|c|}
\hline Channel & DAQPIN & Name & Type & Bundie & Wire & Signal & 110 \\
\hline Cho & 3 & Lift & SE & 5 & brown(1) & AllC & 1 \\
\hline Ch1 & 5 & Drag & SE & 5 & green(3) & AIIC & 1 \\
\hline $\mathrm{Ch} 2$ & 7 & Sideforce & SE & 5 & brown/white(5) & $A / C$ & 1 \\
\hline $\mathrm{Ch} 3$ & 9 & Rollmoment & SE & 5 & white(14) & AIC & 1 \\
\hline Ch4 & 11 & Yawmoment & $\mathrm{SE}$ & 5 & $\operatorname{red}(4)$ & A/IC & 1 \\
\hline Ch11 & 10 & Pitchmoment & SE & 5 & blue(10) & $A / C$ & 1 \\
\hline Ch6 & 15 & Lift & SE & 5 & yellow(9) & $B / I C$ & 1 \\
\hline $\mathrm{Ch} 7$ & 17 & Drag & $\mathrm{SE}$ & 5 & purple(11) & $\mathrm{B} / \mathrm{IC}$ & 1 \\
\hline Ch8 & 4 & Sideforce & SE & 5 & beige(13) & $B / I C$ & 1 \\
\hline Ch9 & 6 & Rollmoment & $\mathrm{SE}$ & 5 & white/bown(6) & $\mathrm{B} / \mathrm{IC}$ & 1 \\
\hline Ch10 & 8 & Yawmoment & SE & 5 & grey(12) & $B / I C$ & 1 \\
\hline Ch5 & 13 & Pitchmoment & SE & 5 & orange(2) & $\mathrm{B} / \mathrm{IC}$ & 1 \\
\hline AGND & 1 & Ground & & 5 & Black(8) & & \\
\hline Ch16/Ch24 & $51 / 52$ & T3 (15") & Diff & 2 & Black(+)/White(-) & & 1 \\
\hline Ch17/Ch25 & $53 / 54$ & T1 (15") & Diff & 2 & Red(+)/Green(-) & & 1 \\
\hline $\mathrm{Ch} 22 / \mathrm{Ch} 30$ & $63 / 64$ & T2(2.5") & Diff & 3 & $\operatorname{Red}(+) /$ Black $(-)$ & & 1 \\
\hline Ch19 & 57 & Alpha & $\mathrm{SE}$ & 4 & White & & 1 \\
\hline Ch18 & 55 & Psi & SE & 4 & DarkGreen & & 1 \\
\hline $\mathrm{Ch} 20$ & 59 & $Y$ & SE & 4 & Brown & & 1 \\
\hline Ch21 & 61 & $\mathrm{z}$ & $\mathrm{SE}$ & 4 & Red & & 1 \\
\hline DACOut & 20 & Motor-Velocity & Binary & 1 & Brown & & $\overline{0}$ \\
\hline Binary(0) & 25 & Select 1 & Binary & 1 & Green & & 0 \\
\hline Binary(1) & 27 & Select 2 & Binary & 1 & White & & 0 \\
\hline Binary(2) & 29 & Motor-On & Binary & 1 & Red & & 0 \\
\hline DGND & 24 & Ground & & 1 & Black & & \\
\hline
\end{tabular}

\subsubsection{Resolution of the Traverse System}

As mentioned above the stepper motors are controlled digitally based on 12 bits. This leads to a theoretical number of

$$
2^{12}=4096
$$

possible steps of the same size available for every motor. Every step indicates a different motor position and thus a different location of the tip of the pitot-static probe. Table 3.3 shows the difference $\Delta L$ between the lowest and the largest possible position of the probe in inches for the $y$ - and z-location as well as the difference $\Delta i$ of the related step counts and the resulting maximum resolution $R_{\max }$ : 


$$
R_{\max }=\frac{\Delta i}{\Delta L}
$$

Table 3.3. Maximum resolution of the pitot-probe motion in $\mathrm{Y}$ - and $\mathrm{Z}$ - direction

\begin{tabular}{|c|c|c|c|c|}
\hline Component & $\Delta L$ [in.] & $\Delta i$ [steps] & $R_{\max }[$ steps/in.] & $\frac{1}{R_{\max }}$ [in./step] \\
\hline$Z$ & 30.5 & 3642 & 119.41 & 0.0083752 \\
\hline $\mathrm{Y}$ & 33 & 3448 & 104.48 & 0.0095708 \\
\hline
\end{tabular}

The resolution of the Z-motion is slightly higher than the value of the $\mathrm{Y}$-motion due to the fact that the tunnel test section height is lower than the horizontal distance from one tunnel wall to the other. The minimum distance the probe can be moved per step achieved is below a hundredth of an inch for both directions, which is sufficient to obtain enough pressure data points within the wake region for an accurate numerical integration.

\subsubsection{Calibration of the Stepper Motors}

To obtain functions that represent the relation between the physical location of a device controlled by a motor and the voltage reading recorded to the data file or the digital step reading used in the software, calibration data has to be determined for every device. The "psi"-position (angle of attack in 2-D test) has been calibrated using degree markings on the turntable driven by the psi-motor. For every position the related voltage has been recorded. The Y- and Z-position of the pitot-static probe has been determined using the plumb bob setup (Figure 3.1.5). The coordinate system used to describe the position of the tip of the pitot-static probe has its origin on the centerline of the tunnel and is shown in Figure 3.1.6.

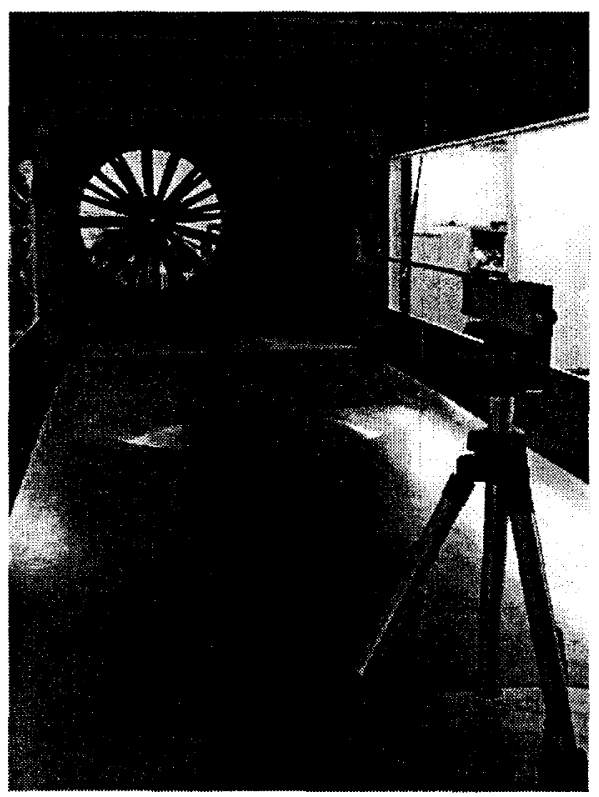

Figure 3.1.5. Laser pointer, pointing at the center of the fan. 


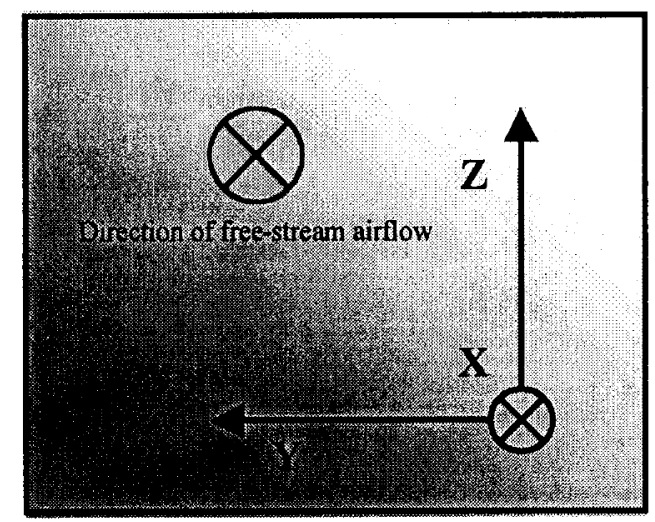

Figure 3.1.6. Pitot-static probe coordinate system.

The distance of the probe from the tunnel center in $y$-direction has been identified using the plumb bob pointing to 1-inch step markings on the tunnel floor, while for the $Z$ direction 1-inch steps have been marked on the plumb bob string itself to determine the vertical distance of the probe from the tunnel center.

The linear regression method applied to the calibration data. The following equations are obtained

$$
\begin{aligned}
& \psi=25.196 V_{\psi}-51.394 \\
& Y=9.6233 V_{Y}-19.946 \\
& Z=8.4425 V_{Z}-17.002
\end{aligned}
$$

where $\mathrm{Y}$ and $\mathrm{Z}$ are the coordinates of the tip of the pitot-static probe in inches, $\psi$ is the angle of yaw (angle of attack in 2-D test) in degrees and $V_{i}$ are the related voltage readings in VDC.

\subsubsection{Flow Field Measurement Hardware Upgrades}

A straight pitot static tube manufactured by the United Sensor Corporation of the type PDD-24-G-21-KL is used for wake analysis. It has a sensing stem diameter of 3/16 in. reinforced up to $0.25 \mathrm{in}$. and an overall length of $24 \mathrm{in}$. The inner tube diameter is 0.095 in.. The four static port orifices located $1.13 \pm 0.02 \mathrm{in}$. from the tip have a diameter of $0.025 \mathrm{in}$. and are distributed equally over the periphery of the tube, while the total pressure port opening is $0.071 \mathrm{in}$. of diameter. This sensor is attached to the traverse mechanism and swept through the wake of the airfoil.

A 7-hole probe was also acquired during the course of the project. Due to flow angularities induced by the microtabs, the 7-hole probe is required to accurately make measurements to conduct the wake-based drag analysis. The probe was custom manufactured and arrived near the end of the project period. Calibration and measurements using the 7-hole probe is in progress at UC Davis. 


\subsubsection{Tunnel Acquisition Interface Software Upgrades}

A new wind tunnel data acquisition (DAQ) interface protocol and documentation was created under this project. The interface tool allows for more accurate and automated data acquisition using LabVIEW ${ }^{\mathrm{TM}}$ and the PC.

Figure 3.1.7 depicts the main interface window that contains separate modules which perform different tasks within the program. Each module allows the user to more easily configure different aspects of the software or visualize the data pertaining to that section.

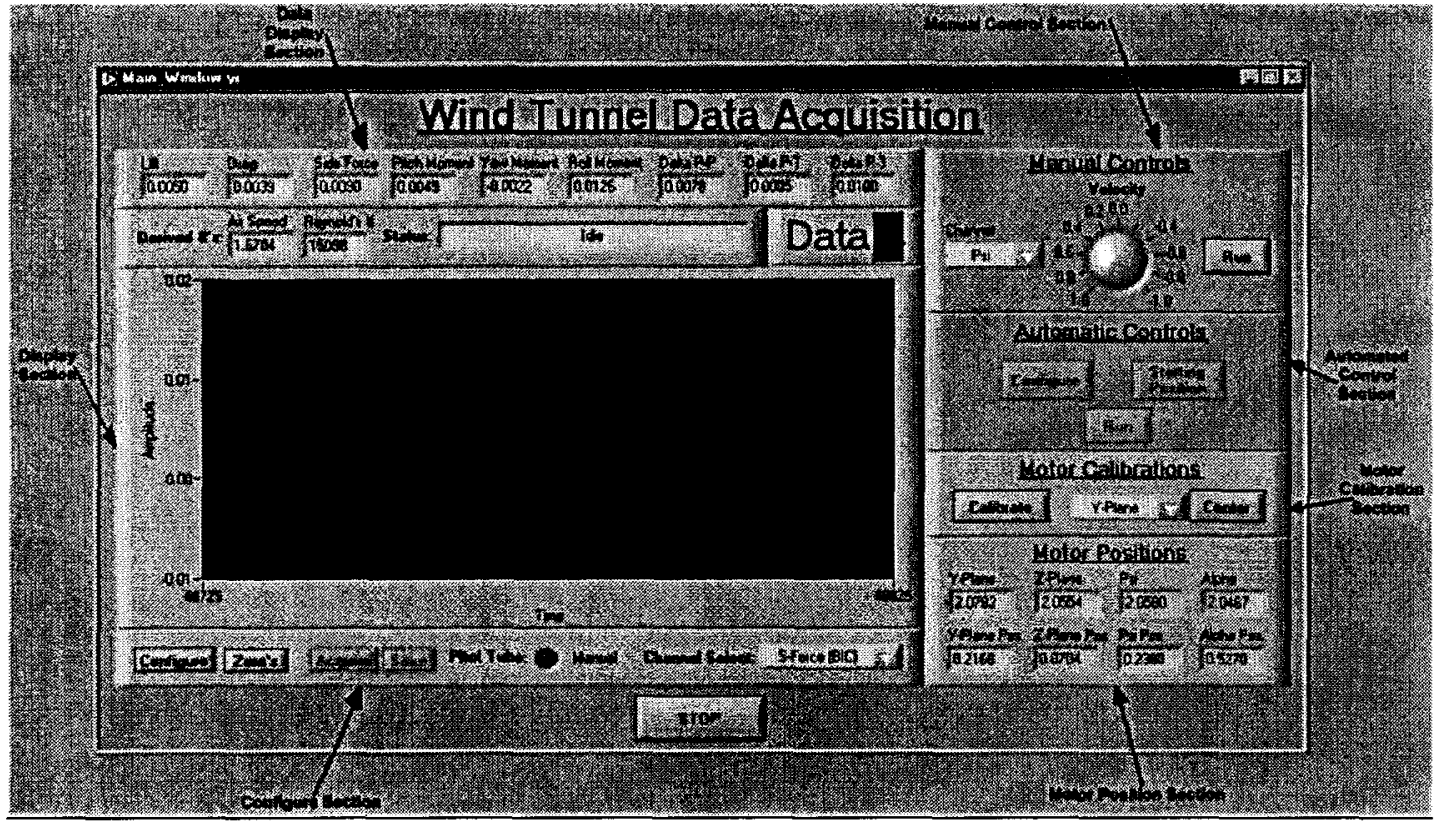

Figure 3.1.7. New wind tunnel data acquisition main interface panel.

The Data Display Section located in the top left corner of the window, is the section where the data from all the sensors can be viewed. All values are both displayed and stored to file in raw form (i.e. voltages), it is up to the user to convert the data to the needed unit. In the bottom part of this section there are also a couple of derived values as well as a status window. The derived values are calculated using the raw data and are not stored to file, while the status window is used as a visual marker indicating in what process the software is working on. Processes range from storing data, automatic routine, and many others. All processes are explained through out the document. The Display Section located in the left center portion of the window is where the data is displayed. This window displays one channel at a time and allows the user the flexibility of different formats. The Configure Section located in the bottom left corner has many independent and unique features. In this section the user can configure the software, zero out the readings, acquire data, and select the channel displayed. Figure 3.1.8 depicts the software flow logic.

In the Manual Control Section the user can control the traverse mechanism manually and mimic the actual controller for the traverse mechanism. Below the manual control is the Automated Control Section. In this section the user can configure the software to operate the traverse mechanism automatically. The user sets the parameters 
and the software takes care of the rest. The Motor Calibration Section located near the right middle part of the window is used to calibrate all the motors in the wind tunnel. Whenever a new experiment is run or calibrations are required this section allows the user to re-calibrate the sensors. The last section the Motor Position Section located in the bottom right corner displays the current position of the motors both in voltage and in inches. When acquiring data, the voltage values are the only values recorded to file.

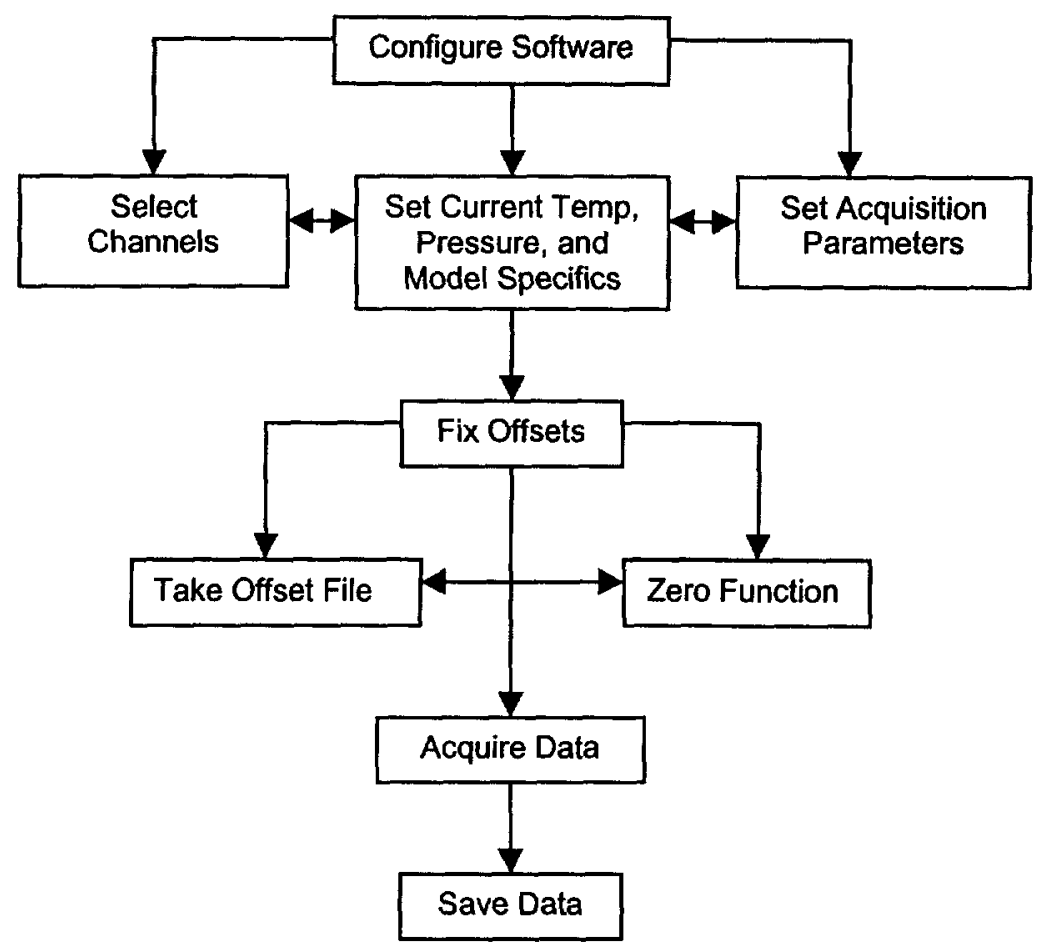

Figure 3.1.8. Wind tunnel interface software protocol.

\subsubsection{Pressure Transducers \& Calibration}

The tunnel is equipped with three SETRA 239 pressure transducers (Table 3.4). All transducers have a nominal output signal of 0 to $5 \mathrm{~V}$. The manufacturer guaranties an accuracy of $\pm 0.4 \%$ of full-scale. The two $15 \mathrm{in}$. $\mathrm{H}_{2} \mathrm{O}$ transducers are used to determine tunnel velocity as well as the differential pressure for the wake analysis. The lower scale transducer of $2.5 \mathrm{in} . \mathrm{H}_{2} \mathrm{O}$ can be used for tunnel velocities not exceeding $65 \mathrm{mph}$.

Table 3.4. Pressure transducers list.

\begin{tabular}{|c|c|}
\hline Transducer & Pressure Scale \\
\hline $\mathrm{T} 1$ & 15 in. $\mathrm{H}_{2} \mathrm{O}$ \\
\hline $\mathrm{T} 2$ & 2.5 in. $\mathrm{H}_{2} \mathrm{O}$ \\
\hline $\mathrm{T} 3$ & 15 in. $\mathrm{H}_{2} \mathrm{O}$ \\
\hline
\end{tabular}


The experimental setup of the pressure transducers can be arranged in two different ways. The first possible setup $(S 1)$, which uses the transducers T1 and T3, is demonstrated in Figure 3.1.9. The transducers are connected to the pitot-static probe and the pressure orifices of the tunnel by vinyl tubes with an inner diameter of $1 / 8$ in. and an outer diameter of 3/16 in. Transducer T1 measures the difference between the tunnel inlet static pressure and the static pressure at the test section inlet, which represents the freestream dynamic pressure $q_{\infty}$ (see V.1). Transducer T3 measures the difference between the total pressure and the static pressure in the in the measurement plane, which is equal to the dynamic pressure $q_{2}$, as needed for the wake analysis.

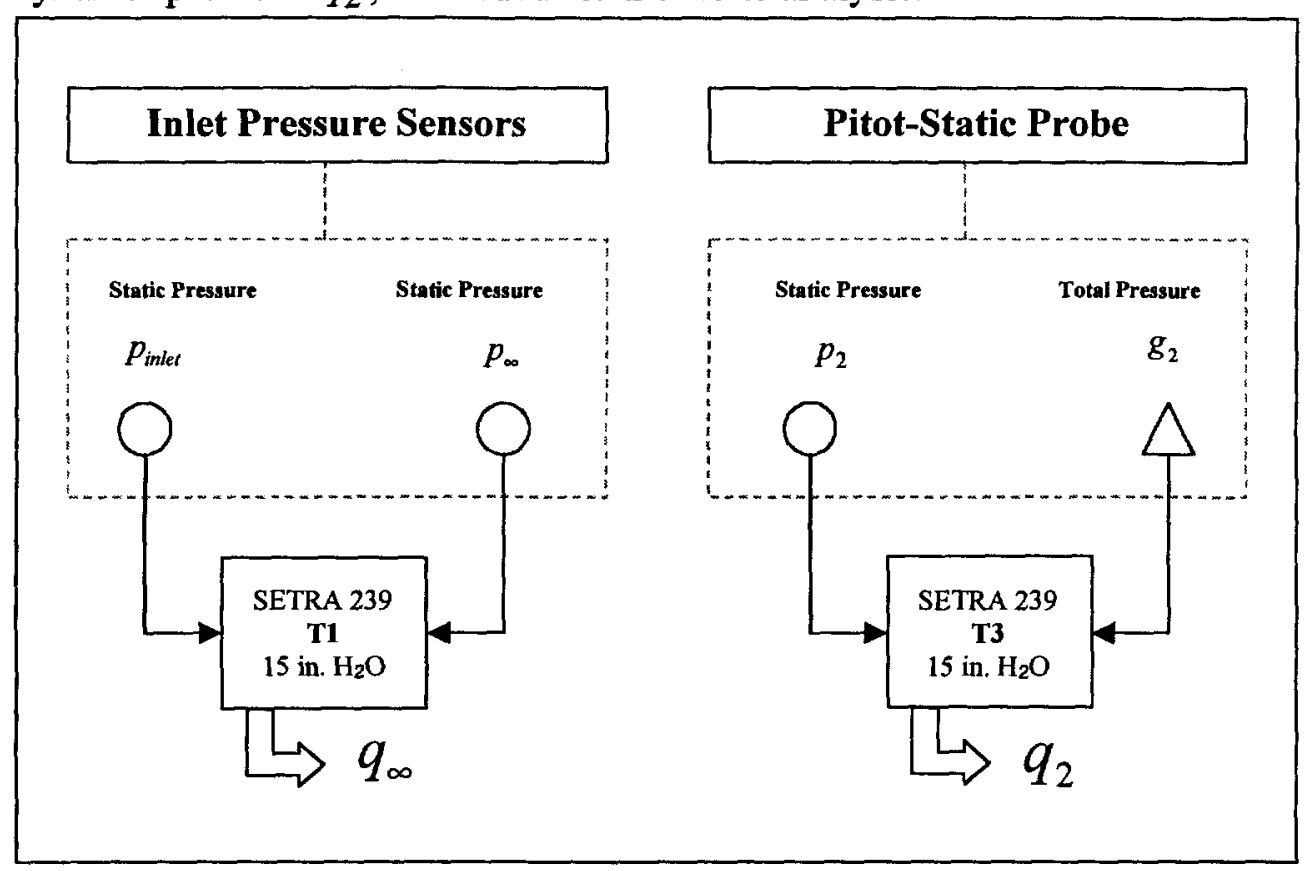

Figure 3.1.9. Setup using transducers $\mathrm{T} 1$ and $\mathrm{T} 3$

The setup including three pressure transducers $(\boldsymbol{S} 2)$ is based on the use of vinyl tubes of the same kind as in setup S1. This setup is shown in Figure 3.1.10. 


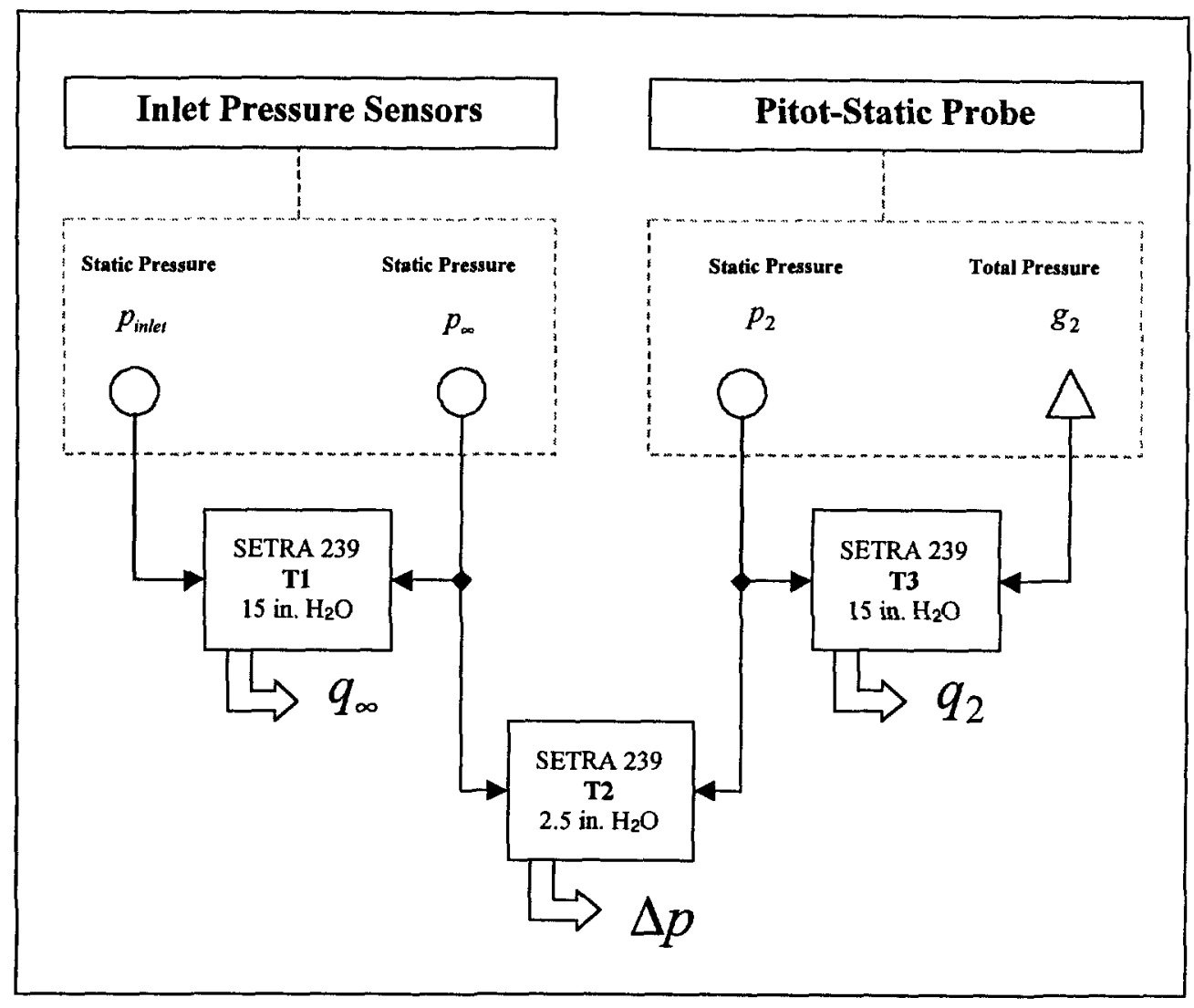

Figure 3.1.10. Setup using transducers $\mathrm{T} 1, \mathrm{~T} 2$ and $\mathrm{T} 3$

To connect the third transducer $T 2$, which additionally measures the difference of the free-stream static pressure $p_{\infty}$ and the static pressure at the measurement plane of the probe $p_{2}$, two union tees are installed in the respective pressure tubes. All tube fittings and adapter fittings used in the pressure circuit are manufactured by SWAGELOK. The differential voltages generated by the pressure transducers can be recorded by the data acquisition system.

The pressure transducers produce a voltage, which is in a linearly dependent on the measured pressure difference. As part of the data reduction process, the pressure difference is calculated from the respective voltage reading. For this purpose the manufacturer provides a set of calibration data.

In the following the method of deriving a calibration equation from the calibration data is presented exemplarily for transducer $\mathrm{T} 1$. The calibration data provided by the manufacturer is listed in Table 3.5. 
Table 3.5. Calibration data of transducer T1

\begin{tabular}{|c|c|}
\hline Pressure [in H2O] & Voltage [VDC] \\
\hline 0.007 & 0.007 \\
\hline 1.6216 & 0.5382 \\
\hline 3.0794 & 1.0245 \\
\hline 4.6353 & 1.5433 \\
\hline 6.2119 & 2.0694 \\
\hline 7.5922 & 2.5309 \\
\hline 9.1976 & 3.0675 \\
\hline 10.5688 & 3.5241 \\
\hline 12.1545 & 4.0532 \\
\hline 13.5068 & 4.5029 \\
\hline 15.1557 & 5.0509 \\
\hline
\end{tabular}

If a linear regression is applied to the dataset we obtain the plot shown in Figure 3.1.11 To derive a linear function for the pressure the approach

$$
y=a+b x
$$

is applied, where $x$ and $y$ represent the voltage and the pressure respectively. The task is now to pick the values for $a$ and $b$ in a way that the sum of squared vertical deviations of the calibration data from the fitted line $\mathrm{S}^{2}$ is minimized dependent on $a$ and $b$.

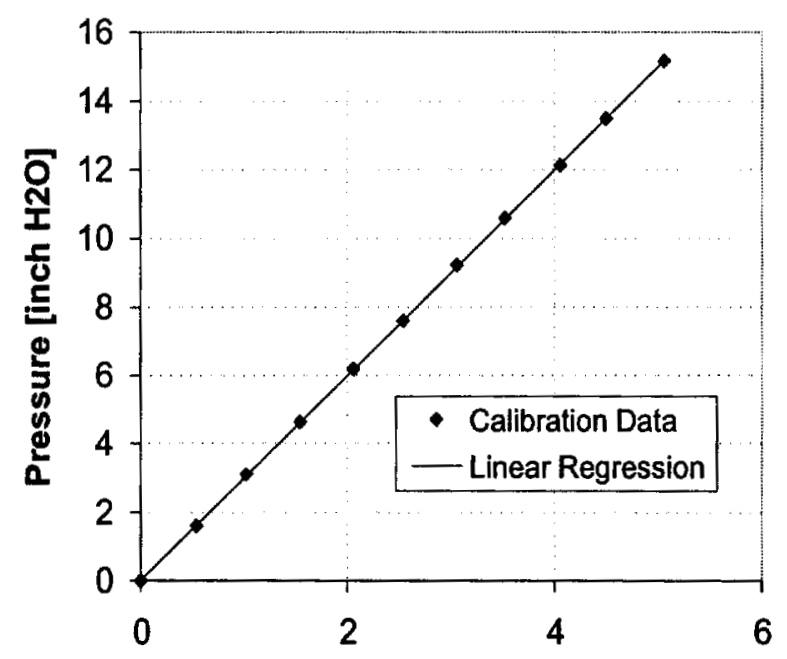

Figure 3.1.11. Linear regression of the calibration data for transducer $\mathrm{T} 1$

$$
\mathrm{S}^{2}=\sum_{i=1}^{n}\left[y_{i}-y\left(x_{i}\right)\right]^{2}=\sum_{i=1}^{n}\left[y_{i}-\left(a+b x_{i}\right)\right]^{2}
$$


The approach

$$
\mathrm{d}\left(\mathrm{S}^{2}\right)=0
$$

delivers the desired information

$$
a=\frac{\sum y_{i} \sum x_{i}^{2}-\sum x_{i} \sum x_{i} y_{i}}{n \sum x_{i}^{2}-\left(\sum x_{i}\right)^{2}} \quad \text { and } \quad b=\frac{n \sum x_{i} y_{i}-\sum x_{i} \sum y_{i}}{n \sum x_{i}^{2}-\left(\sum x_{i}\right)^{2}}
$$

The results for transducer $\mathrm{T} 1$ are

$$
a=-0.00003 \quad \text { and } \quad b=2.9998 \text {. }
$$

The calibration data and the linear regression for the transducers T2 and T3 can be reviewed in Appendix B. Additionally, the pressure transducers produce an initial offset $O_{i}$ in the voltage reading even if no pressure difference is applied. These offsets are recorded and subtracted from the actual voltage measurements throughout the experiment in the LabVIEW software.

Finally, the different calibration equations used in the data reduction are:

$$
\begin{array}{lll}
\text { T1 } & : & y_{1}=2.9998\left(x_{1}-O_{1}\right)-3 \times 10^{-5} \\
\text { T2 } & : & y_{2}=0.5\left(x_{2}-O_{2}\right)+3 \times 10^{-4} \\
\text { T3 } & : & y_{3}=3.0001\left(x_{3}-O_{3}\right)+0.002
\end{array}
$$

The above equations deliver the pressure differences $y_{i}$ in the unit of in. $\mathrm{H}_{2} \mathrm{O}$ for given transducer voltages in VDC.

\subsubsection{Determining Drag Coefficients}

The theoretical method using the three pressure transducers is applied to calculate drag coefficients for different airfoil configurations. The equation for drag is shown below.

$$
c_{D}=2 \int \sqrt{\frac{q_{2}}{q_{\infty}}}\left(1-\sqrt{\frac{q_{2}-\Delta p}{q_{\infty}}}\right) d\left(\frac{y}{c}\right)
$$

Figure 3.1.12 shows a typical plot of the dynamic pressure in the wake $q_{2}$ divided by the free-stream velocity $q_{\infty}$ versus the dimensionless coordinate $\frac{y}{c}$ for the clean $S 809$ airfoil at $\alpha=8^{\circ}$ and $\mathrm{Re}=856,000$ taken at $\mathrm{z}=0$. According to the pressure distribution around the airfoil, the level of dynamic pressure is higher on the suction side (upper surface) than on 
the pressure side (lower surface), which does not allow an easy determination of the location of the disturbed wake portion.

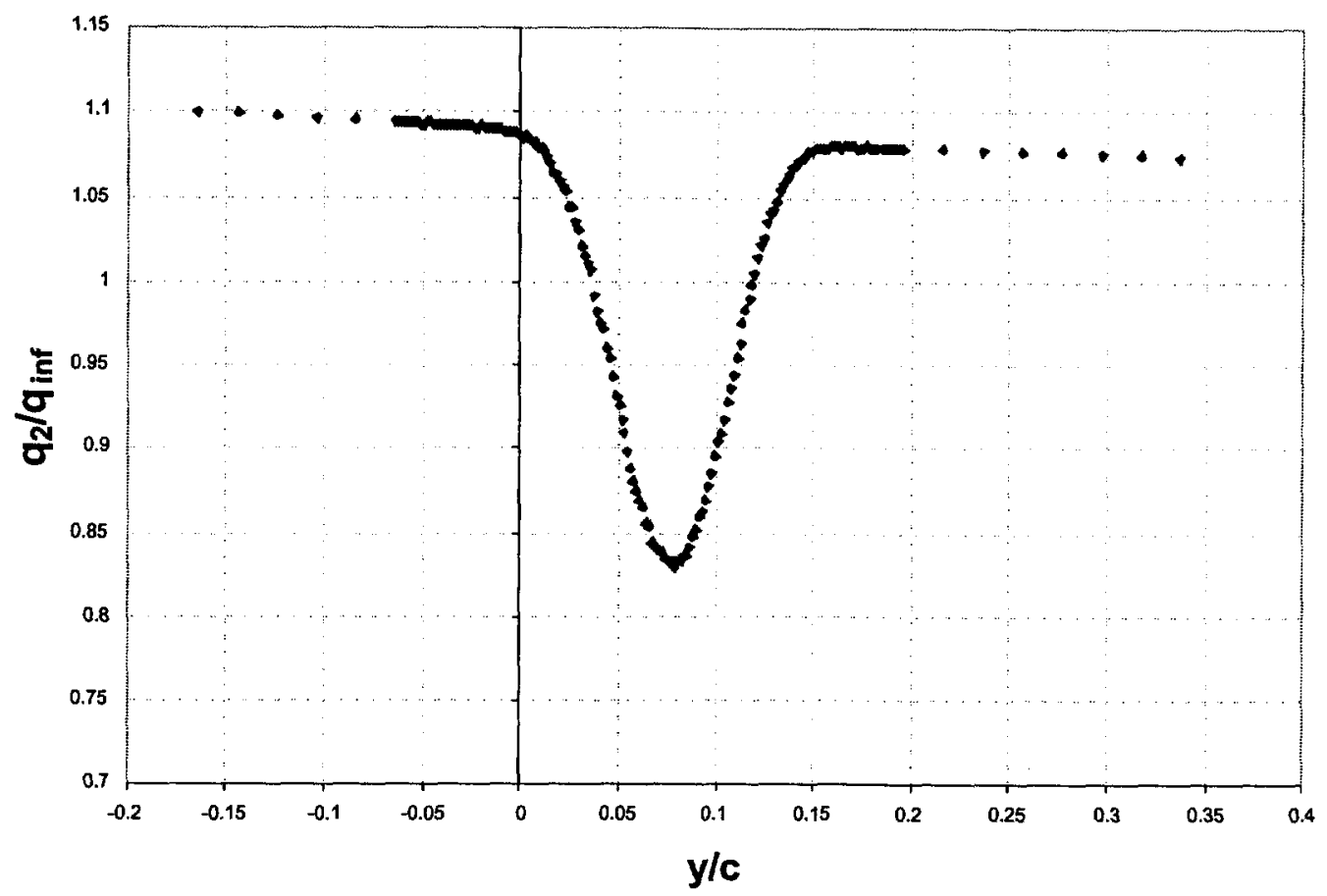

Figure 3.1.12. Dynamic pressure in the wake vs. $y / c$ at $z=0, S 809$ clean configuration at $\alpha=8^{\circ}$ and $\operatorname{Re}=856,000$

To determine the edges of this wake region and the respective integration limits the integrand of equation $A$ is calculated for every data set and is plotted vs. the dimensionless coordinate $\frac{y}{c}$ as demonstrated in Figure 3.1.13.

$$
I=\frac{d c_{D}}{d(y / c)}=2 \sqrt{\frac{q_{2}}{q_{\infty}}}\left(1-\sqrt{\frac{q_{2}-\Delta p}{q_{\infty}}}\right)
$$

It can be observed, that the information derived by the use of three pressure transducers in combination with method M4 is sufficient to provide a profile of the integrand that differs from zero only in the disturbed portion of the wake, even if the dynamic pressure behind the airfoil changes significantly in $y$-direction. 


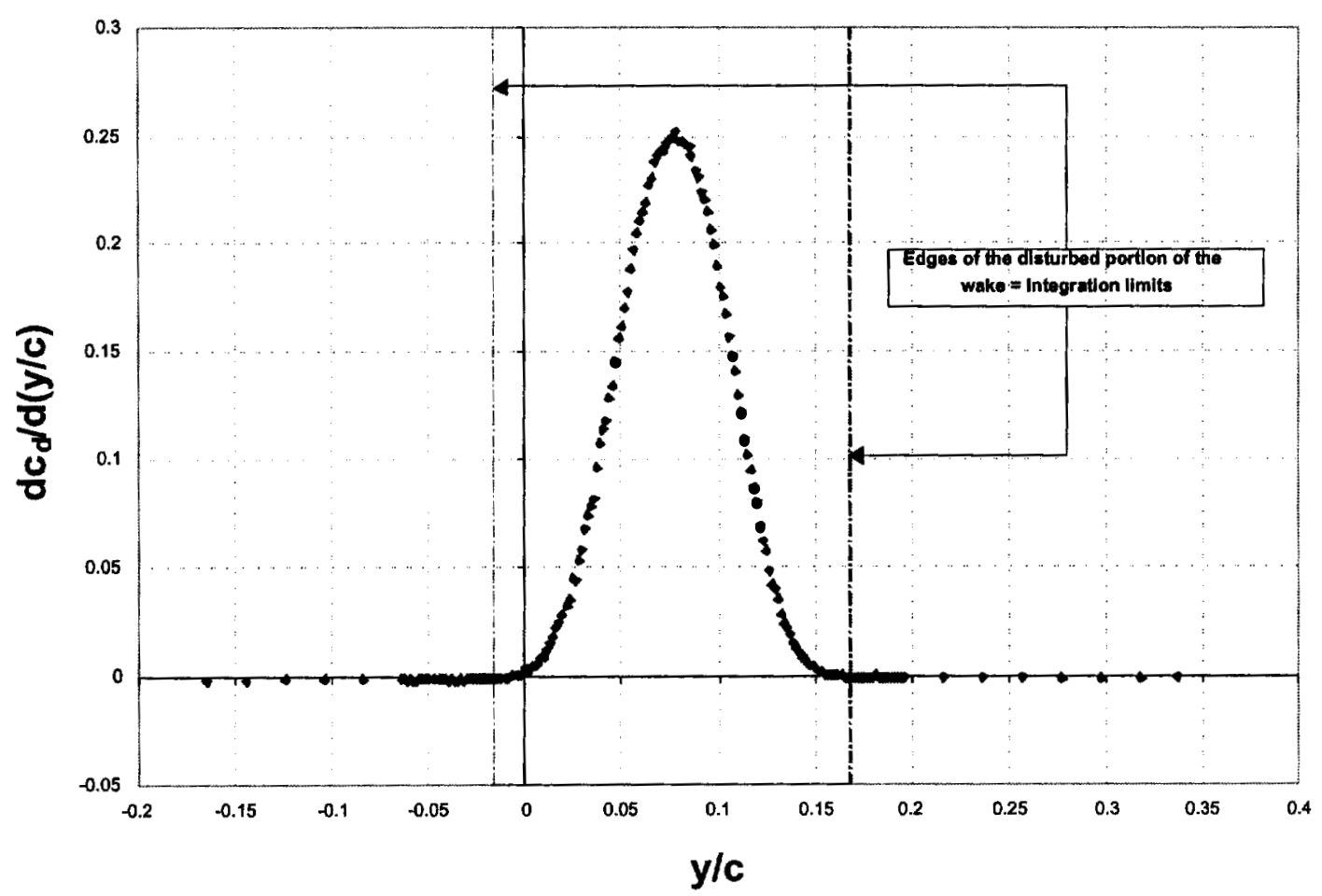

Figure 3.1.13. Integrand of the drag coefficient vs. $y / c$ at $z=0, S 809$ clean configuration at $\alpha=8^{\circ}$ and $\operatorname{Re}=856,000$.

To minimize the effect of uncertainty errors on the drag coefficients, the integration is only conducted over this disturbed portion of the wake. The integrand is analyzed and integration limits are determined for every single configuration tested. In the above example configuration, the integration limits turned out to be

$$
\left(\frac{y}{c}\right)_{\text {left }}=-0.018 \quad \text { and } \quad\left(\frac{y}{c}\right)_{\text {right }}=0.166 \text {. }
$$

Finally, the integration is realized numerically applying the trapezoidal rule to the data within the integration limits

$$
c_{D}=\sum_{i=l}^{r-1} \frac{\left(I_{i}+I_{i+1}\right)}{2}\left(\left(\frac{y}{c}\right)_{i+1}-\left(\frac{y}{c}\right)_{i}\right),
$$

where $r$ and $l$ are the indices of the datasets belonging to the right and the left integration limit respectively.

Summarizing the results of the uncertainty analysis for the variables discussed in the following chapter $\left(C_{L}, C_{M}\right.$, and $\left.I\left(\Rightarrow C_{D}\right)\right)$, as well as the Reynolds number are presented in Table 3.6. 
Table 3.6. Summary of uncertainty results

\begin{tabular}{|c|c|c|c|c|}
\hline Result & Value & $\begin{array}{c}\text { Total } \\
\text { Uncertainty } U_{r}\end{array}$ & $\begin{array}{c}\text { Uncertainty } \\
\text { in \% }\end{array}$ & Main Error Source \\
\hline$C_{L}$ & 0.59121 & 0.005649 & 0.955 & $\begin{array}{c}\text { elemental bias limit } \\
\text { of } T 1\end{array}$ \\
\hline$C_{M}$ & -0.06329 & 0.001518 & 2.398 & $\begin{array}{c}\text { elemental bias limit } \\
\text { due to data curve fit }\end{array}$ \\
\hline$I\left(C_{D}\right)$ & 0.22164 & 0.01088665 & 4.912 & $\begin{array}{c}\text { elemental bias limit } \\
\text { of T1 and T3 }\end{array}$ \\
\hline$R e$ & $1,021,025$ & 6417.94 & 0.629 & $\begin{array}{c}\text { elemental bias limit } \\
\text { of T1 }\end{array}$ \\
\hline
\end{tabular}

It is interesting to see that the uncertainty of the results is mainly influenced by the elemental bias error of the pressure transducers given by the manufacturer $(0.4 \%$ of full scale $\Rightarrow>0.02 \mathrm{VDC}$ ). A reason might be that the typical range for the voltage readings of the pressure transducers in the conducted experiments ranges only between 0.5 and 2.5 VDC. This increases the unavoidable error in the voltage readings of the transducers. Note the resolution of the wake measurements used for determining the drag coefficient (Figure 3.1.14).

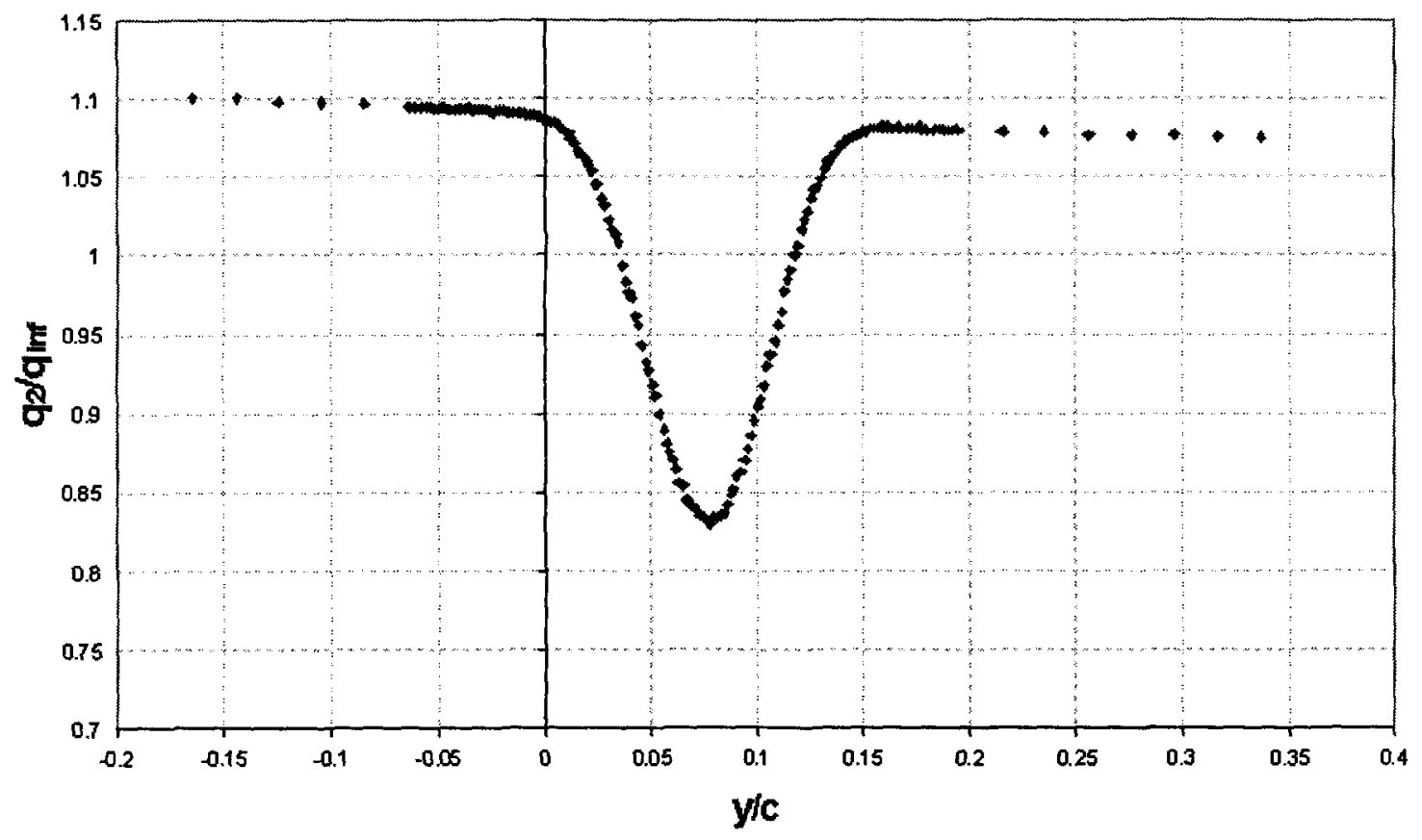

Figure 3.1.14. Wake base analysis using the automated routine. Note the resolution. 


\subsubsection{Experiment Validation Drag Results}

\section{UPPER SURFACE}

The upper surface coefficient of drag is presented in tabular form. This is due to the fact that for every configuration only five different angles of attack in the linear region of the lift curve have been taken into account. Assuming that the uncertainty concerning the drag coefficient can be expected to be about $5 \%$ resulting in 6 to 15 drag counts (depending on the absolute drag value) for the conducted tests, the discussion of the drag results focuses more on general tendencies and trends. The effect of the tab installation on the upper surface is presented in Table 3.7.

Table 3.7. S809, drag results, tab height $1.04 \%$, upper surface, $\mathrm{Re}=856,000$

\section{Clean Airfoil}

\begin{tabular}{|c|c|c|c|c|}
\hline$\alpha$ & $C_{L}$ & $C_{D}$ & $C_{m}$ & $C_{L} / C_{D}$ \\
\hline-2 & -0.078 & 0.0117 & -0.040 & -6.6 \\
\hline 0 & 0.124 & 0.0111 & -0.045 & 11.2 \\
\hline 2 & 0.354 & 0.0117 & -0.051 & 30.3 \\
\hline 4 & 0.586 & 0.0132 & -0.061 & 44.5 \\
\hline 8 & 0.988 & 0.0172 & -0.066 & 57.5 \\
\hline
\end{tabular}

Loc0\%, Hgt1.04\%

\begin{tabular}{|c|c|c|c|c|}
\hline$\alpha$ & $C_{L}$ & $C_{D}$ & $C_{m}$ & $C_{L} / C_{D}$ \\
\hline-2 & -0.351 & 0.0165 & 0.030 & -21.3 \\
\hline 0 & -0.103 & 0.0166 & 0.021 & -6.2 \\
\hline 2 & 0.108 & 0.0169 & 0.011 & 6.4 \\
\hline 4 & 0.340 & 0.0165 & 0.002 & 20.7 \\
\hline 8 & 0.888 & 0.0169 & -0.038 & 52.6 \\
\hline
\end{tabular}

\section{Loc10\%, Hgt $1.04 \%$}

\begin{tabular}{|c|c|c|c|c|}
\hline$\alpha$ & $C_{L}$ & $C_{D}$ & $C_{m}$ & $C_{L} / C_{D}$ \\
\hline-2 & -0.263 & 0.0187 & -0.010 & -14.0 \\
\hline 0 & -0.037 & 0.0190 & -0.015 & -2.0 \\
\hline 2 & 0.168 & 0.0194 & -0.021 & 8.7 \\
\hline 4 & 0.394 & 0.0195 & -0.030 & 20.2 \\
\hline 8 & 0.873 & 0.0196 & -0.051 & 44.6 \\
\hline
\end{tabular}

\section{Loc5\%, Hgt $1.04 \%$}

\begin{tabular}{|c|c|c|c|c|}
\hline$\alpha$ & $C_{L}$ & $C_{D}$ & $C_{m}$ & $C_{L} / C_{D}$ \\
\hline-2 & -0.289 & 0.0179 & 0.001 & -16.2 \\
\hline 0 & -0.057 & 0.0180 & -0.006 & -3.2 \\
\hline 2 & 0.152 & 0.0183 & -0.013 & 8.3 \\
\hline 4 & 0.377 & 0.0183 & -0.021 & 20.7 \\
\hline 8 & 0.885 & 0.0183 & -0.050 & 48.5 \\
\hline
\end{tabular}

Loc15\%, Hgt $1.04 \%$

\begin{tabular}{|c|c|c|c|c|}
\hline$\alpha$ & $C_{L}$ & $C_{D}$ & $C_{m}$ & $C_{L} / C_{D}$ \\
\hline-2 & -0.237 & 0.0208 & -0.017 & -11.4 \\
\hline 0 & -0.028 & 0.0212 & -0.020 & -1.3 \\
\hline 2 & 0.172 & 0.0218 & -0.024 & 7.9 \\
\hline 4 & 0.403 & 0.0222 & -0.032 & 18.2 \\
\hline 8 & 0.873 & 0.0217 & -0.049 & 40.2 \\
\hline
\end{tabular}

For the clean airfoil the drag does almost not change within the range between $\alpha=-2^{\circ}$ and $\alpha=2^{\circ}$. At higher angles of attack it shows a significant increase with $\alpha$. This behavior changes if tabs are installed. It can be observed, that for a particular tab configuration the drag level does not change much throughout the range of angle of attack.. This is an interesting observation, as it shows that the drag penalty especially at angles of attack around $\alpha=8^{\circ}$ is relatively small, which can be verified looking at the lift-to-drag ratio, $C_{L} / C_{D}$. As the tabs have a changing influence on the drag level, that increases with the distance from the trailing edge, the tabs should be installed as close as possible to the trailing edge in order to minimize the drag penalty and increase the effect on lift at the same time. 
Table 3.1.8 shows the influence of the tab height on the drag results. One general tendency is that an increasing tab height leads to a higher drag level and lower lift-to-drag ratios. At the same time it has a decreasing effect on the lift causing the drag penalty to increase. For a tab height of $2.08 \%$ of chord the drag coefficient decreases about 40 counts between $\alpha=4^{\circ}$ and $\alpha=8^{\circ}$. This could be explained by the fact that the tab is entering the separated region of the flow leading to a drag coefficient that is mainly influenced by the lift produced in this case.

Table 3.1.8. S809, drag results, location 5\%, upper surface, $\operatorname{Re}=856,000$

Clean Alrfoil

\begin{tabular}{|c|c|c|c|c|}
\hline$\alpha$ & $C_{L}$ & $C_{D}$ & $C_{m}$ & $C_{L} / C_{D}$ \\
\hline-2 & -0.078 & 0.0117 & -0.040 & -6.6 \\
\hline 0 & 0.124 & 0.0111 & -0.045 & 11.2 \\
\hline 2 & 0.354 & 0.0117 & -0.051 & 30.3 \\
\hline 4 & 0.586 & 0.0132 & -0.061 & 44.5 \\
\hline 8 & 0.988 & 0.0172 & -0.066 & 57.5 \\
\hline
\end{tabular}

Loc5\%, Hgt $1.56 \%$

\begin{tabular}{|c|c|c|c|c|}
\hline$\alpha$ & $C_{L}$ & $C_{D}$ & $C_{m}$ & $C_{L} / C_{D}$ \\
\hline-2 & -0.354 & 0.0196 & 0.028 & -18.0 \\
\hline 0 & -0.098 & 0.0198 & 0.019 & -4.9 \\
\hline 2 & 0.118 & 0.0204 & 0.011 & 5.8 \\
\hline 4 & 0.343 & 0.0205 & 0.003 & 16.7 \\
\hline 8 & 0.868 & 0.0206 & -0.031 & 42.2 \\
\hline
\end{tabular}

\section{LOWER SURFACE}

The drag results are presented in the same way as for the upper surface tabs. Table 3.1.9 shows the influence of the lower surface tab location on the drag coefficient for a tab height of $1.04 \%$ of chord. The tabs generally increase the drag. The change in drag is almost constant for an angle of attack up to 4 degrees. At $\alpha=8^{\circ}$ a significant jump in drag occurs, causing a drop in the lift-to-drag ratio, $C_{L} / C_{D}$. The reason for this jump in drag is that at $\alpha=8^{\circ}$ the flow over the airfoil with the tab is stalled. It can be observed, that in contrast to the installation of the tabs on the upper surface, the drag level changes only very slightly depending on the tab location throughout the regarded range of angle of attack. As the tabs have an effect on the lift coefficient that is decreasing with the distance from the trailing edge the tabs should be installed as close as possible to the trailing edge in order to minimize the drag penalty. For the same reason a too high angle of attack should be avoided.

Loc5\%, Hgt $1.04 \%$
\begin{tabular}{|c|c|c|c|c|}
\hline$\alpha$ & $C_{L}$ & $C_{D}$ & $C_{m}$ & $C_{L} / C_{D}$ \\
\hline-2 & -0.289 & 0.0179 & 0.001 & -16.2 \\
\hline 0 & -0.057 & 0.0180 & -0.006 & -3.2 \\
\hline 2 & 0.152 & 0.0183 & -0.013 & 8.3 \\
\hline 4 & 0.377 & 0.0183 & -0.021 & 20.7 \\
\hline 8 & 0.885 & 0.0183 & -0.050 & 48.5 \\
\hline
\end{tabular}

Loc5\%, Hgt $2.08 \%$

\begin{tabular}{|c|c|c|c|c|}
\hline$\alpha$ & $C_{L}$ & $C_{D}$ & $C_{m}$ & $C_{L} / C_{D}$ \\
\hline-2 & -0.417 & 0.0262 & 0.042 & -15.9 \\
\hline 0 & -0.154 & 0.0264 & 0.034 & -5.8 \\
\hline 2 & 0.066 & 0.0257 & 0.023 & 2.6 \\
\hline 4 & 0.281 & 0.0264 & 0.015 & 10.6 \\
\hline 8 & 0.821 & 0.0221 & -0.022 & 37.2 \\
\hline
\end{tabular}


Table 3.1.9. $\mathrm{S} 809$, drag results, tab height $1.04 \%$, lower surface, $\mathrm{Re}=856,000$

Clean Airfoil

\begin{tabular}{|c|c|c|c|c|}
\hline$\alpha$ & $C_{L}$ & $C_{D}$ & $C_{m}$ & $C_{L} / C_{D}$ \\
\hline-2 & -0.078 & 0.0117 & -0.040 & -6.6 \\
\hline 0 & 0.124 & 0.0111 & -0.045 & 11.2 \\
\hline 2 & 0.354 & 0.0117 & -0.051 & 30.3 \\
\hline 4 & 0.586 & 0.0132 & -0.061 & 44.5 \\
\hline 8 & 0.988 & 0.0172 & -0.066 & 57.5 \\
\hline
\end{tabular}

Loc5\%, Hgt $1.04 \%$

\begin{tabular}{|c|c|c|c|c|}
\hline$\alpha$ & $C_{L}$ & $C_{D}$ & $C_{m}$ & $C_{L} / C_{D}$ \\
\hline-2 & 0.041 & 0.0152 & -0.059 & 2.7 \\
\hline 0 & 0.272 & 0.0154 & -0.065 & 17.7 \\
\hline 2 & 0.505 & 0.0160 & -0.076 & 31.5 \\
\hline 4 & 0.755 & 0.0163 & -0.085 & 46.4 \\
\hline 8 & 1.167 & 0.0251 & -0.095 & 46.4 \\
\hline
\end{tabular}

\section{Loc0 $\%$, Hgt $1.04 \%$}

\begin{tabular}{|c|c|c|c|c|}
\hline$\alpha$ & $C_{L}$ & $C_{D}$ & $C_{m}$ & $C_{L} / C_{D}$ \\
\hline-2 & 0.215 & 0.0168 & -0.107 & 12.7 \\
\hline 0 & 0.487 & 0.0169 & -0.121 & 28.7 \\
\hline 2 & 0.731 & 0.0164 & -0.133 & 44.6 \\
\hline 4 & 0.985 & 0.0165 & -0.144 & 59.5 \\
\hline 8 & 1.359 & 0.0296 & -0.150 & 45.8 \\
\hline
\end{tabular}

Loc10\%, Hgt1.04\%

\begin{tabular}{|c|c|c|c|c|}
\hline$\alpha$ & $C_{L}$ & $C_{D}$ & $C_{m}$ & $C_{L} / C_{D}$ \\
\hline-2 & -0.018 & 0.0154 & -0.038 & -1.1 \\
\hline 0 & 0.184 & 0.0154 & -0.041 & 12.0 \\
\hline 2 & 0.411 & 0.0161 & -0.046 & 25.4 \\
\hline 4 & 0.637 & 0.0166 & -0.051 & 38.3 \\
\hline 8 & 0.949 & 0.0234 & -0.036 & 40.6 \\
\hline
\end{tabular}

Table 3.1.10 shows the influence of the tab height on the drag results. One general tendency is that an increasing tab height leads to a higher drag level and the same steep rise as mentioned above can be observed for $\alpha=8^{\circ}$. In order to analyze the efficiency of the tabs the lift to drag ratio $C_{L} / C_{D}$ is examined.

Table 3.1.10. $\mathrm{S} 809$, drag results, location $5 \%$, lower surface, $\mathrm{Re}=856,000$

Clean Airfoil

\begin{tabular}{|c|c|c|c|c|}
\hline $\boldsymbol{\alpha}$ & $\mathbf{C}_{\mathrm{L}}$ & $\mathbf{C}_{\mathrm{D}}$ & $\mathbf{C}_{\mathrm{m}}$ & $\mathbf{C}_{\mathrm{L}} / \mathbf{C}_{\mathrm{D}}$ \\
\hline-2 & -0.078 & 0.0117 & -0.040 & -6.6 \\
\hline 0 & 0.124 & 0.0111 & -0.045 & 11.2 \\
\hline 2 & 0.354 & 0.0117 & -0.051 & 30.3 \\
\hline 4 & 0.586 & 0.0132 & -0.061 & 44.5 \\
\hline 8 & 0.988 & 0.0172 & -0.066 & 57.5 \\
\hline
\end{tabular}

Loc $5 \%, \mathrm{Hgt} 1.56 \%$

\begin{tabular}{|c|c|c|c|c|}
\hline$\alpha$ & $C_{L}$ & $C_{D}$ & $C_{m}$ & $C_{L} / C_{D}$ \\
\hline-2 & 0.131 & 0.0177 & -0.083 & 7.4 \\
\hline 0 & 0.386 & 0.0180 & -0.095 & 21.5 \\
\hline 2 & 0.626 & 0.0180 & -0.106 & 34.7 \\
\hline 4 & 0.888 & 0.0189 & -0.117 & 47.0 \\
\hline 8 & 1.306 & 0.0292 & -0.130 & 44.7 \\
\hline
\end{tabular}

Loc5\%, Hgt1.04\%

\begin{tabular}{|c|c|c|c|c|}
\hline$\alpha$ & $C_{L}$ & $C_{D}$ & $C_{m}$ & $C_{L} / C_{D}$ \\
\hline-2 & 0.041 & 0.0152 & -0.059 & 2.7 \\
\hline 0 & 0.272 & 0.0154 & -0.065 & 17.7 \\
\hline 2 & 0.505 & 0.0160 & -0.076 & 31.5 \\
\hline 4 & 0.755 & 0.0163 & -0.085 & 46.4 \\
\hline 8 & 1.167 & 0.0251 & -0.095 & 46.4 \\
\hline
\end{tabular}

\section{Loc5\%, Hgt $2.08 \%$}

\begin{tabular}{|c|c|c|c|c|}
\hline$\alpha$ & $\mathbf{C}_{L}$ & $\mathbf{C}_{D}$ & $\mathbf{C}_{m}$ & $C_{L} / \mathbf{C}_{D}$ \\
\hline-2 & 0.185 & 0.0209 & -0.094 & 8.9 \\
\hline 0 & 0.435 & 0.0216 & -0.109 & 20.2 \\
\hline 2 & 0.683 & 0.0229 & -0.120 & 29.8 \\
\hline 4 & 0.934 & 0.0240 & -0.131 & 38.9 \\
\hline 8 & 1.361 & 0.0312 & -0.147 & 43.7 \\
\hline
\end{tabular}

This ratio increases with the tab height up to $1.56 \%$ of chord and drops again in case of the largest tab. It could be subject to further research to determine the optimum, which can be expected. It is remarkable that in case of a tab height of $1.56 \%$ of chord the significant increase in the coefficient of lift of about 0.25 in the linear region of the lift curve at low angles of attack between $\alpha=-2^{\circ}$ and $\alpha=4^{\circ}$ does not lead to a drop in lift to drag ratio. 


\subsection{NUMERICAL SIMULATION [6]}

This section briefly outlines the computational tools that are being used in the current project and some preliminary results using these codes. The focus is implementing and developing grids for the microtab using these numerical methods that solve the Reynolds-averaged Navier-Stokes (RANS) equations.

\subsubsection{Grid Generator \& Numerical Solvers}

The primary grid generation tool used in this study is a program called OVERGRID that was developed by William M. Chan at NASA Ames Research Center [7]. OVERGRID serves as a valuable tool for visualizing, constructing, manipulating, and diagnosing many types of grids and geometries. Computational simulations using structured overset grids typically involve multiple steps and a variety of software modules. A graphical interface called OVERGRID has been specially developed for such purposes. Data required and created by the different steps include geometry, grids, domain connectivity information and flow solver input parameters. The interface provides a unified environment for the visualization, processing, generation and diagnosis of such data. General modules are available for the manipulation of structured grids and unstructured surface triangulations. Modules more specific for the overset approach include surface curve generators, hyperbolic and algebraic surface grid generators, a hyperbolic volume grid generator, Cartesian box grid generators, and domain connectivity pre-processing tools.

The OVERGRID interface belongs to a larger software package called Chimera Grid Tools (CGT) [8]. The CGT package consists of about 40 independent grid generation and solution analysis modules that run in batch mode, the OVERGRID graphical interface, a suite of scripts that can be used for automating overset-grid computations on complex configurations, and several libraries of common routines shared by the various tools.

INS2D and OVERFLOW are two RANS solvers extensively used in this project. INS2D was developed by Rogers and Kwak at the NASA Ames Research Center $[9,10]$. The code solves the incompressible, two-dimensional, Reynolds-averaged Navier-Stokes equations in generalized curvilinear coordinates using the artificial compressibility method of Chorin [11] to couple the velocity and pressure fields. The convective fluxes are upwind differenced using a third-order flux-difference splitting scheme developed by Roe [12] and the viscous fluxes are central differenced in standard second-order form. The resulting equations are solved by implicit line-relaxation sweeps. The code can handle both multi-block patched grids as well as overset Chimera grids and has been applied extensively to analyze flows over single and multi-element airfoils [13-17].

OVERFLOW is a three-dimensional, compressible RANS flow solver developed by Buning et al. at NASA [18]. Use of three identical computational planes in the spanwise direction permits the modeling of two-dimensional flows. Steady and timeaccurate solutions can be calculated on structured block or Chimera overset grids. In this study, all computations are conducted on Chimera overset grids with a centraldifferencing block tri-diagonal scheme. Artificial dissipation $\left(2^{\text {nd }}\right.$ order dissipation coefficient: $0.00 ; 4^{\text {th }}$ order dissipation coefficient: 0.04 ) is used to aid numerical stability.

OVERFLOW includes several zero-, one-, and two-equation turbulence models including two versions of the Spalart-Allmaras one-equation turbulence model [19] 
differing in how transition is specified $[18,20]$. The first version introduces a transition term that regulates the transition from laminar to turbulent flow. Hence, there is no need to artificially suppress turbulence production with an "intermittency" function. In addition, a smooth progression from laminar to turbulent flow is provided at the userspecified transition points. This transition method tends to cause transition to extend over too long a distance; therefore, the second transition model is preferred. The second transition model uses an "intermittency" function, ranging from zero to one, that multiplies the turbulence production term in order to obtain a smooth variation in the flow variables at transition onset. The function is zero upstream of the specified transition points, corresponding to a laminar flow region, and scales to unity directly downstream of the transition onset location, corresponding to a turbulent region. The default intermittency function for this model is a short ramp (based on the grid index along the wall).

\subsubsection{Numerical Simulations}

Further numerical and experimental research needs to be conducted to fully explore the benefits of the microtabs. Although the lift enhancement effects have been demonstrated, research is ongoing to develop an integrated micro-electrical-mechanical (MEM) actuation system. Test results show the desired lift enhancement effects may be obtained without adverse moment variations; however, dynamic control and response as well as 3-D microtab gap spacing effects on lift and drag warrant further investigation using a 3-D tool such as OVERFLOW. Current studies using OVERFLOW are looking to validate previous work in 2-D and then to extend the studies to 3-D. Previous work indicated that retaining a slight gap and modifying the tab shape (i.e., serrated shape) may help to decrease overall drag and that continuous solid tabs may not be required for 3-D configurations [21,22]. Recent observations of dragonflies in nature also allude to this fact [23]. Optimizing the gap sizing between microtabs may provide a way to increase lift without significant drag penalties. Two-dimensional and three-dimensional grid development and simulation work is in progress to explore and analyze various tab shape and tab spacing configurations (Figure 3.2.1). Steady as well as time accurate scenarios are expected to yield deeper understanding of the aerodynamic load response capabilities using the microtabs.

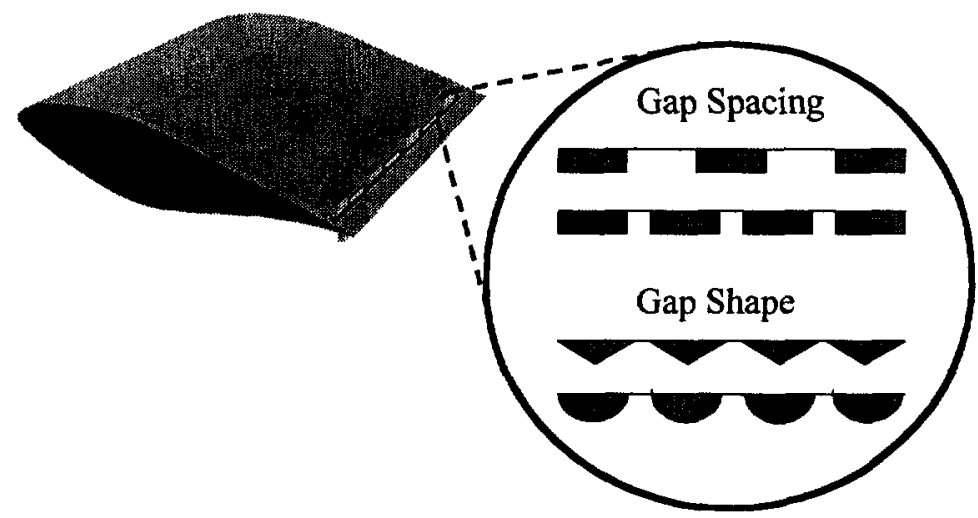

Figure 3.2.1. 3-D microtab gap spacing and gap shape configurations. 


\section{Two Dimensional Study}

Two-dimensional simulations using OVERFLOW have been conducted for the S 809 airfoil with tabs, $\mathrm{h} / \mathrm{c}=1.0 \%$ and a tab width of $0.2 \%$, placed on the lower surface at $95 \%$ of chord for a Reynolds number of $1 \times 10^{6}$. Figure 3.2 .1 shows one of the overset grids used in the study corresponding to a $0^{\circ}$ angle of attack with a close-up of the trailing edge region. Results for this study indicate similar trends previously observed both computationally and experimentally for the GU airfoil. Streamlines of the flow solution calculated on the grid in Figure 3.2.2 are shown in Figure 3.2.3. As seen before, the separated, recirculating flow under the trailing edge is effectively modifying the Kutta condition in a manner consistent with an increase in camber. Similar studies are presently being conducted with tabs located on the upper surface. Future efforts will also investigate the effect of tabs near the leading edge.

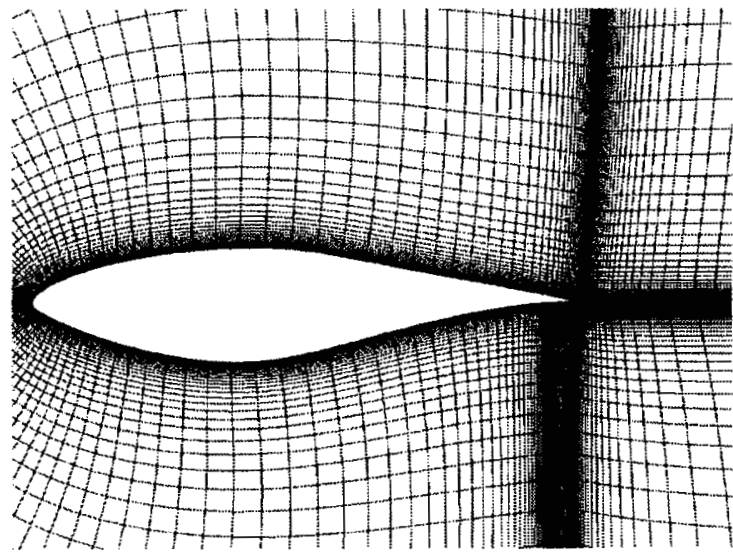

(a)

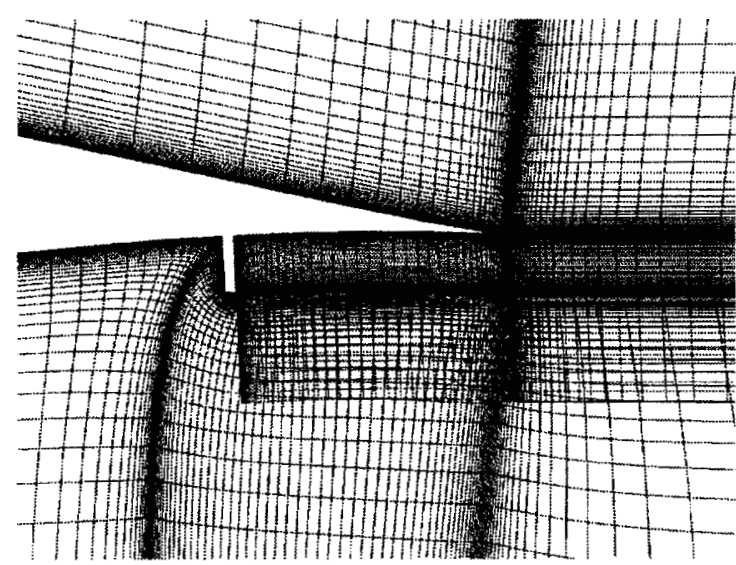

(b)

Figure 3.2.2. a) Overset grids for the $\mathrm{S} 809$ airfoil with a $\mathrm{tab}(\mathrm{h} / \mathrm{c}=1 \%)$ placed on the lower surface at $95 \%$ of chord, b) close-up of overset grids.

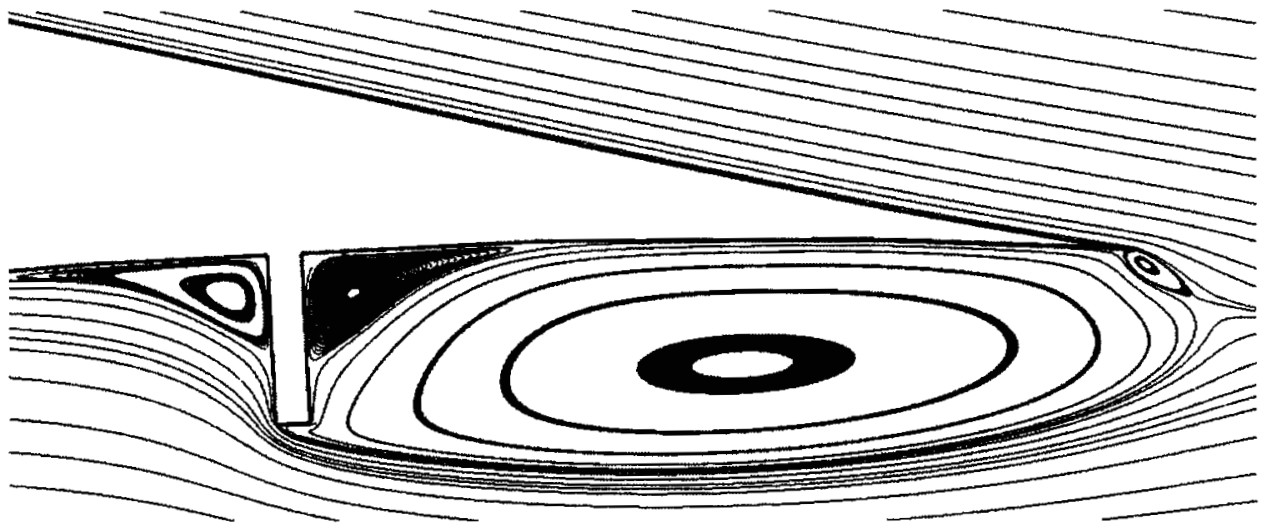

Figure 3.2.3. Detailed streamlines for the $\mathrm{S} 809$ airfoil with tab ( $\mathrm{h} / \mathrm{c}=1 \%$ ) placed at $95 \%$ of chord at $0^{\circ}$ angle of attack for a Reynolds number $1 \times 10^{6}$. 


\section{Three Dimensional Study}

Simulations using OVERFLOW are aimed at addressing the following issues: 1) insight into tab gap and downstream wake effects, 2) tab effects on drag reduction, 3) gap spacing and gap shape parameters and 4) time accurate response frequencies.

Initial 3-D overset grids have been generated using OVERGRID. Figure 13 shows the baseline airfoil defined using 3 grids, the front box grid, C-mesh for the airfoil and a fanned wake grid. Preliminary results (Figure 3.2.4) show that the 3-grid approach provides a balance in maximizing grid resolution and computational efficiency by minimizing grid points.

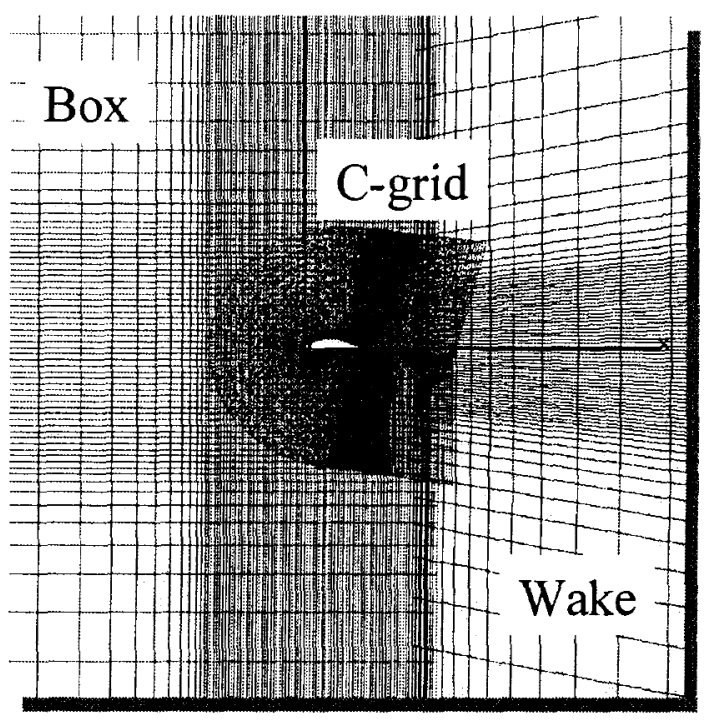

(a)

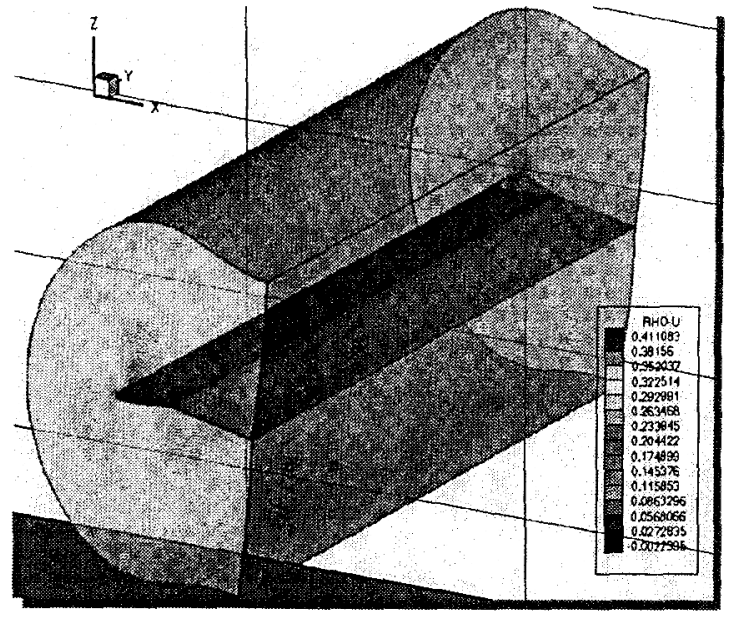

(b)

Figure 3.2.4. a) 3-D overset grids for modeling airfoil and microtabs, b) preliminary 3-D airfoil simulations using OVERFLOW.

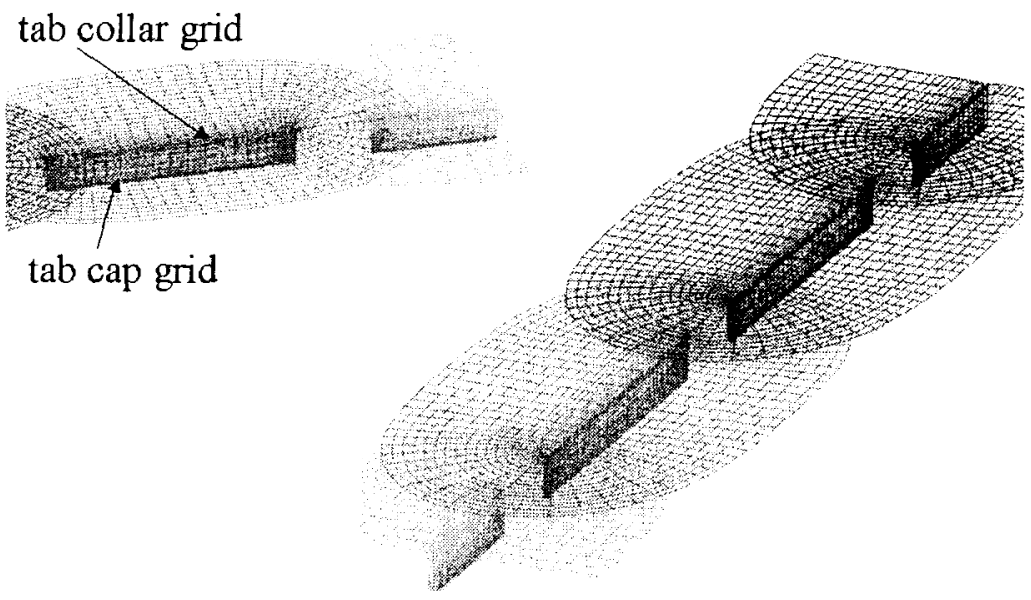

Figure 3.2.5. Chimera grids for the microtabs.

Figure 3.2.5 depicts details for the microtab grid. Using a tab cap and tab collar and an embedded wake aft of the tab, the additional grids and clustered points should 
provide sufficient resolution to capture the details of the vortices and wake interactions. Simulations using the Chimera grid approach and a partial span airfoil with 2 full rectangular tabs and 2 half tabs at the boundary interfaces are currently underway.

\subsection{MICROTAB \& ACTUATOR DEVELOPMENT [24]}

Throughout the years, trailing edge devices of various geometries and materials have been proposed and studied for the purposes of lift enhancement and control, but many are exploratory and impractical for implementation. For load control applications, robust devices with quick activation and response times, and low installation and maintenance costs are desired. For this project, a two-position ON-OFF device has been conceptualized and fabricated. Initially, mechanical rotating devices as well as flap-like devices were considered; however, the small sizes, the tight interchange ability tolerances, and the total number of devices needed proved to be a manufacturing challenge. Instead, a microfabrication manufacturing approach more suitable to mass production is utilized.

The current microtab assembly consists of three pieces: a base, a slider, and an extender (Figure 3.3.1). Utilizing the standard microfabrication technique of anisotropic silicon wet etching, excellent precision, a high degree of repeatability, and mass production manufacturing are achieved.

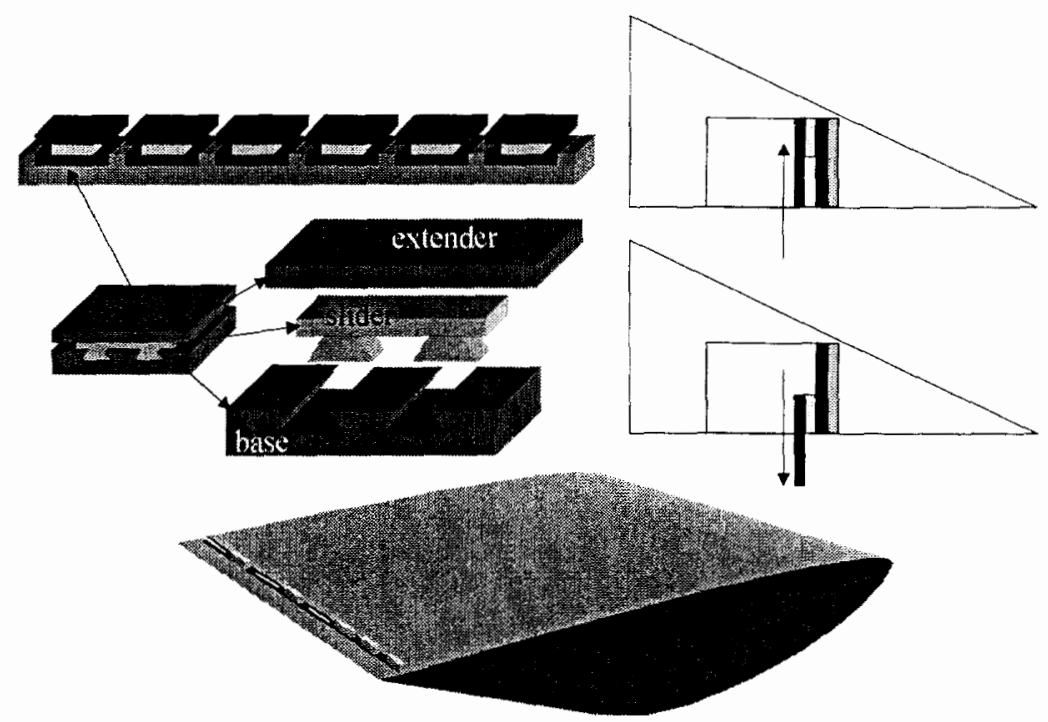

Figure 3.3.1. Three-piece tab shown in extended and retracted position. Tab assembly consisting of a base, slider, and extender in a modular track assembly.

The base and slider are the microfabricated pieces which define the dovetail joint. While almost any single-crystalline material such as gallium arsenide, germanium, quartz, and metal may be used to create the dovetails, the mechanical properties, electronic properties, purity, and etch geometry of $\langle 100\rangle$ silicon is ideal for this application. The dovetail structures are formed using an etching process that is dependent on crystallographic orientation or anisotropic etching. 


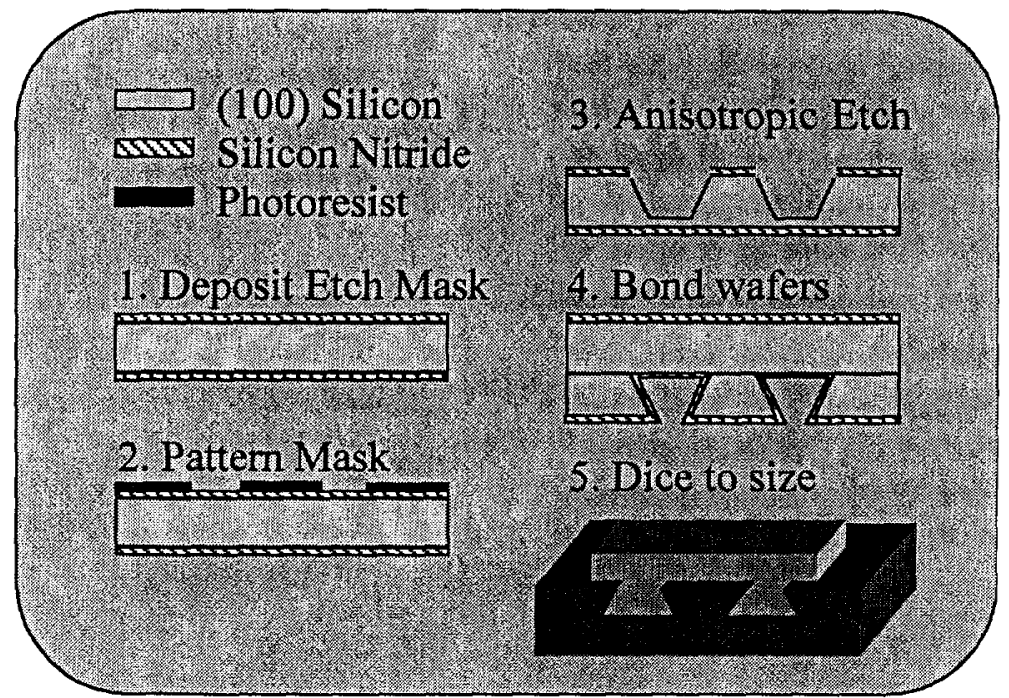

Figure 3.3.2. Microtab fabrication process flow showing dovetail design.

Figure 3.3.2 illustrates the process flow for the fabrication of the dovetail joint. Using low-pressure chemical vapor deposition (LP-CVD), a silicon nitride etch mask is deposited and patterned on a $<100>$ silicon wafer. Using potassium hydroxide $(\mathrm{KOH})$ at $60{ }^{\circ} \mathrm{C}$, the wafer is anisotropically etched to the desired depth. The $<100>$ plane etches 400 times faster than the $<111>$ plane. Because of the differing etch rates for each crystalline orientation, precise dovetail joints with characteristic angles of $54.7^{\circ}$ are formed with a tolerance within $1 \mu \mathrm{m}$ [25]. After the etch is completed, the nitride is stripped. Next, using silicon fusion bonding, the wafer is bonded to a second wafer. The silicon that is exposed is thinned with $\mathrm{KOH}$ to open the dovetails. Finally, the wafers are diced and assembled.

Great care is taken to fabricate the dovetail joints. The primary issues in this microfabrication process include the precision of the initial mask patterns, timing of the anisotropic etching, and proper alignment of the photo mask to the crystal plane.

Prolonged exposure to the $\mathrm{KOH}$ or misaligning the mask will cause undercutting which results in a widening of the dovetail structures. In order to reduce the amount of error, a two-mask process was developed. The first mask consists of using a "wagon wheel" which has etch keys to improve the alignment of the etch masks to the $<110>$ plane. With this technique, the tolerance is within $1 \mu \mathrm{m}$. The alternative process of using a single mask has a tolerance of $\pm 5 \mu \mathrm{m}$.

To complete the tab assembly, the extender is cut to dimensions from a singlesided polished silicon wafer. It is then bonded to the slider. The extender is the only portion of the device that is exposed to the flow. The dovetail structure inherently locks and constrains the slider from unintentional separation. In order to avoid stiction problems, the dovetail joints are coated with $0.1 \mathrm{~mm}$ of LP-CVD silicon nitride. Figure 8 b shows the final assembly of the microtabs after installation in the wind tunnel model. The total dimensions of each assembly are $20 \mathrm{~mm} \times 5 \mathrm{~mm} \times 1.2 \mathrm{~mm}$. Approximately $30 \mathrm{tab}$ assemblies are needed to cover the wind-tunnel model discussed below. While silicon was utilized in this research project, the design is flexible and allows interchanging a wide variety of materials in future applications [1]. 


\subsubsection{Actuator Design \& Development [26]}

Design of robust actuators for microtabs demand new MEMs approaches and integration of macro- and micro-scale concepts. For micro-devices, electromagnetic and electro-mechanical systems are predominant due to their minute size and application compatibility. Large electronic, hydraulic, pneumatic, and mechanical systems have been the conventional means of control actuation. Since these controls are continuously exposed to large fluctuating loads and cyclic conditions, they require significant actuation power and tend to be large and heavy. For the microtabs, actuation methods need to first meet extension requirements, $\mathrm{O}(1 \%$ of section chord $)$ as well as activation force, $\mathrm{O}(1 \mathrm{~N}$ depending on tab size). With target voltage limits, cost, space, and weight as additional design constraints, many of the actuation options fail to meet critical design objectives or are considered undesirable for microtab actuation. For example, a design requiring compressed air canisters or hydraulic reservoirs is not desired. High power consumption (high voltage and/or high current) devices are also considered undesirable for microtab actuation.

The overall design goals for the microtabs is to provide a low power, high frequency, lightweight, and quick response actuation system. Currently, several actuation methods are under investigation including thermo-pneumatic, thermal expansion, electromagnetic, electrostatic, piezoelectric, magnostatic, electrothermo, electromechanical, and shape memory alloy. Unfortunately, none of these meet all of the design criteria specified. Yet, with design improvements, the electro-magnetic and electro-mechanical methods have great potential. This project will continue to investigate the previously developed methods and through the evolution of design, create an innovative actuation system for the microtabs.

Microfabricated actuators developed for the project have the potential of being small, fast and providing high work output in the translational distance and force output. They also have the benefits of avoiding the fluidic containment issues that conventional MEMs actuators, including thermalhydraulic and pneumatic actuators, entail. The development of microfabricated actuators that have translational distances on the order of millimeters and providing force requirements on the order of $0.5 \mathrm{~N}$ will have tremendous impact in the manner and fashion in which MEMs devices can be applied in the macroenvironment. To fully realize the benefit of the microtabs, a micro actuation system must be integrated. The goal, therefore, is to design and build a complete system consisting of the actuation system and the microtabs.

For micro-devices, electromagnetic and electro-mechanical systems are predominant due to their minute size and application compatibility. For applications such as load control for wind turbines, large electronic, hydraulic, pneumatic, and mechanical systems have been the conventional means of control actuation. Since these controls are continuously exposed to large fluctuating loads and cyclic conditions, they require significant actuation power and tend to be large and heavy. For the microtabs, actuation methods need to first meet extension requirements, on the order of $1 \%$ of section chord as well as activation force, on the order of $1 \mathrm{~N}$ depending on tab size. With target voltage limits, cost, space, and weight as additional design constraints, many of the actuation options fail to meet critical design objectives or are considered undesirable for MicroTab 
actuation. For example, a design requiring compressed air canisters or hydraulic reservoirs is not desired. High power consumption (high voltage and/or high current) devices are also considered undesirable for MicroTab actuation.

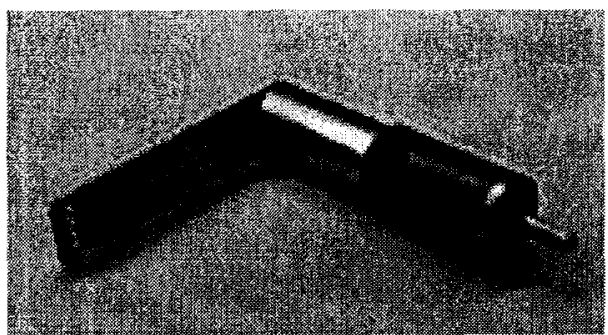

(a)

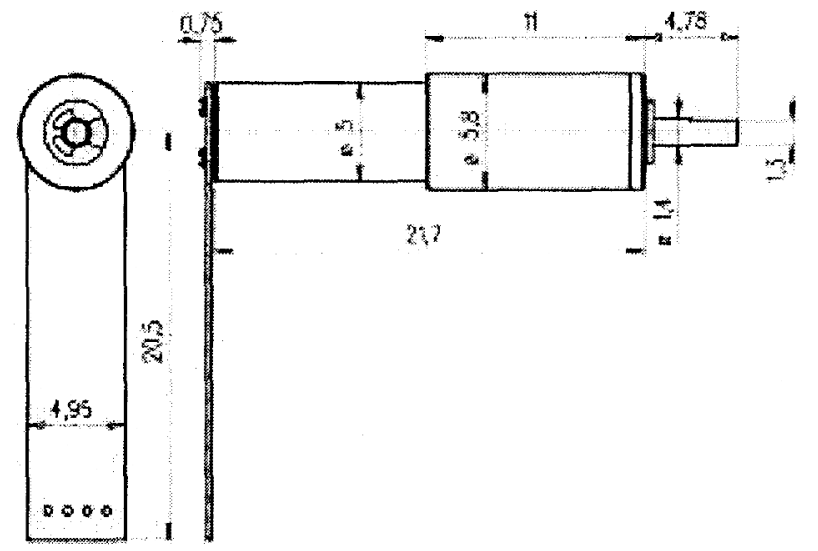

(b)

Fig. 3.3.3: a) BL2S5.025.R.1 Smoovy MicroMotor and b) motor dimensions.

A Smoovy MicroMotor ${ }^{\circledR}$ model number BL2S5.025.R.1 illustrated in Fig. 3.3.3 is utilized to provide the actuation. The motor is a bidirectional, brushless DC motor with planetary gears. It has a diameter of $5 \mathrm{~mm}$, has a gear ratio of $1: 25$, and is capable of producing $15 \mathrm{mN}$ of force with $1.2 \mathrm{mN}$ of continuous torque at nominal voltage of 5 V. Attached to the Smoovy MicroMotor ${ }^{\circledR}$ is a machined nylon spur gear. The spur gear is placed on the motor shaft using a plastic tubing material with an inner diameter of 1 $\mathrm{mm}$. The purpose of the tubing is to allow spur gears or additional shafts to be attached to the motor in a semi-permanent manner for easily exchanging parts during experimentation. Figure 3.3.4 illustrates the modification made to the motor shaft. Experiments were performed with a Smoovy MicroMotor which had a 1:1 gear ratio. Because the amount of actuation distance is significantly less as compared to the force, it is concluded that a gear reduction of at least $1: 25$ is necessary.

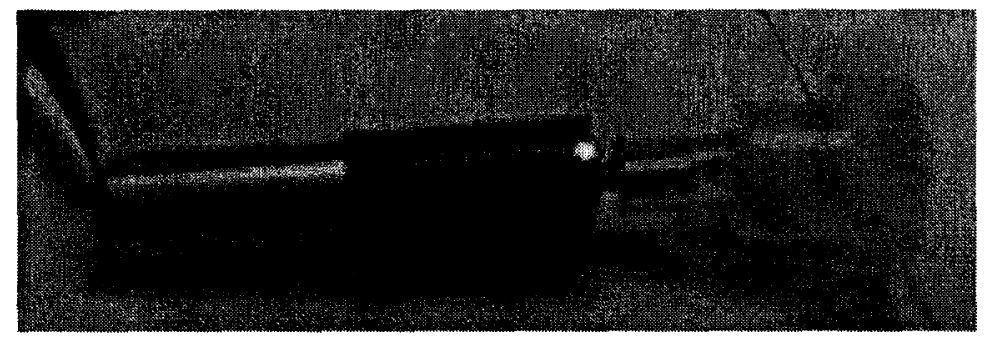

Figure 3.3.4: Smoovy MicroMotor with spur gear.

In order to control the motor, the Smoovy CPS00002 controller is utilized. Figure 3.3.5 is a picture of the controller and circuit diagram illustrating the different components. For this project, it is necessary to have a sensor to turn the motor on and off. 


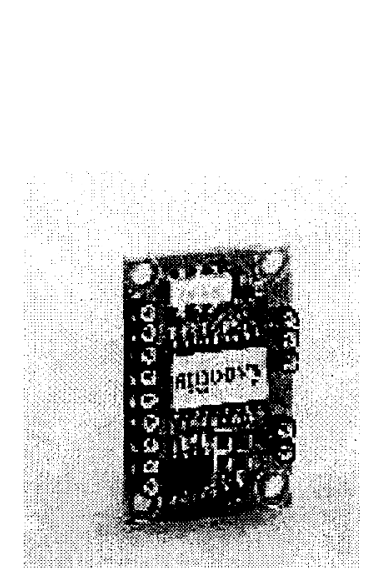

(a)

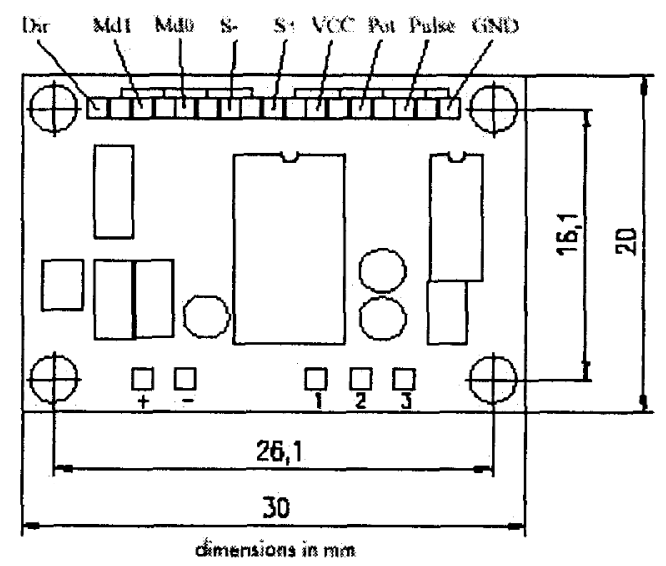

(b)

Figure 3.3.5. a) Smoovy Controller and b) circuit diagram.

Two optical sensors as shown in Figure 3.3.6 are used. The sensor consists of an emitter and receiver. When the light is blocked by a flag, the sensor sends an output signal. The signals from the sensors are placed through a logic circuit, Figure 3.3.6b, which is then connected to the controller. Flags are attached to the same shaft as the tabs. When the tabs are fully extended, a flag blocks Sensor 1 causing the motor to turn off. When the switch is turned to activate the tabs to a fully retracted position, the flag from Sensor 1 is removed while a flag for Sensor 2 blocks the transmitted light again stopping the motor. It is necessary to have sensors to stop and start the motor instead of relying on timing, rotation counting, etc. because a sensor helps to prevent errors. While timing the system to measure how long it takes to extend and retract the tab is an option, additional and varying forces will create error in the system. In the same context while determining distance traveled to control the motor, if power is cut to the system, the controller would risk losing its place causing error in the system.

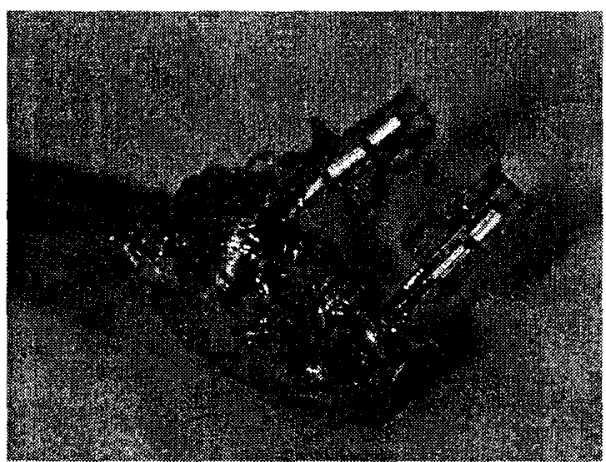

(a)

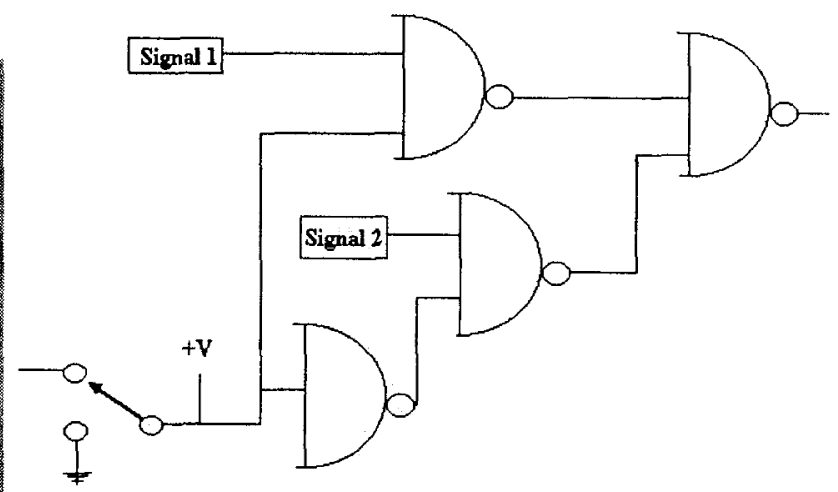

(b)

Figure 3.3.6. a) Optical sensors and b) logic circuit for sensor.

The tabs may be actuated in an array or individually. Three modes of transmission are being developed: rack and pinion, pulley, and hook and rod. Figure 3.3.7 shows a track connected to the extender tab and dovetail joint. This method allows for easy conversion between independent and array tab auction. For independent tab 
actuation, the motor with the spur gear may be directly attached to the tab. In order to move an entire array, several spur gears may be attached to a shaft. The rack and pinion method has several disadvantages. First of all, care must be taken to ensure that debris does not get into the track. Fatigue and warping will occur with the repeated force on the teeth of the track. Finally, finding an adhesive to connect the nylon track to the silicon is difficult as few materials adhere to nylon. Metal tracks have been investigated, but they add a significant amount of weight.

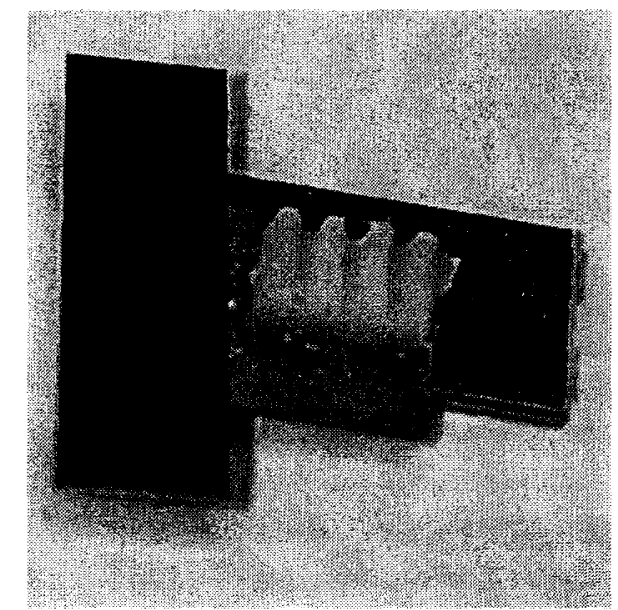

Figure 3.3.7: Dovetail with attached track.

Future work includes integrating the rack and pinion system in the microfabrication process by using a procedure known as UV-LIGA or "poor man's LIGA" developed in the mid-1990s by a group at IBM. LIGA, a German acronym that stands for Lithographic Galvonoformung Abformung, (or lithography, electroplating, molding) is a technique that can be used to produce molds for the fabrication of micromachined components. It is a high aspect ratio MEMS technology combining integrated circuit lithography and electroplating and molding to obtain depth, precise geometry, and smooth, vertical sidewalls. With this new fabrication ability, the geometric constraints in MEMS design has virtually disappeared, thus, allowing for optimal design to minimize stress by configuring the pressure angle, thickness, width, and height of the gear tooth. LIGA allows the use of materials other than silicon such as metals and plastics, opening the door for many different types of structures and devices. However, this process requires an X-ray source from a synchrotron. In the UV-LIGA process, a photoresist that is much thicker and able to withstand more chemical etching is used with standard lithography procedures to get the same effects and aspect ratios as seen with the synchrotron X-ray LIGA process.

Figure 3.3.8 is a close-up view of how the tab had to be temporarily modified in order to accommodate the pulley system. Because a string had to be attached to the tab, it was necessary to make some modifications. In future work, the "star" will not appear as holes will be "drilled" through the silicon tab to allow for string attachment and a groove will be etched in the dovetail to allow the string to be on the surface of the dovetail track instead of over and above it. Figure 3.3.9 is a picture of the utilizing nylon string to extend and retract the tabs by creating a pulley system. The string is present at both the top and bottom of the dovetail to pull for both extension and retraction. Again, a 
spur gear is used to connect the shaft to the motor. This method is slightly more complicated than the rack and pinion method. It is best used in an array method since it relies on a shaft. Yet, it is the most light weight method as the only additional attachment to the tabs is the nylon string.

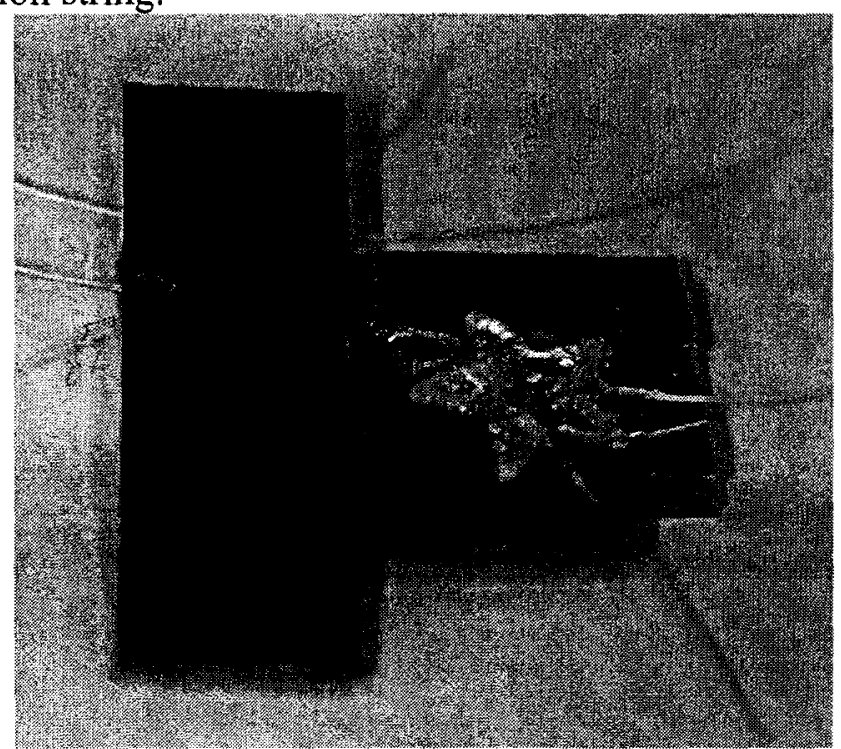

Figure 3.3.8: Tab with pulley modification.

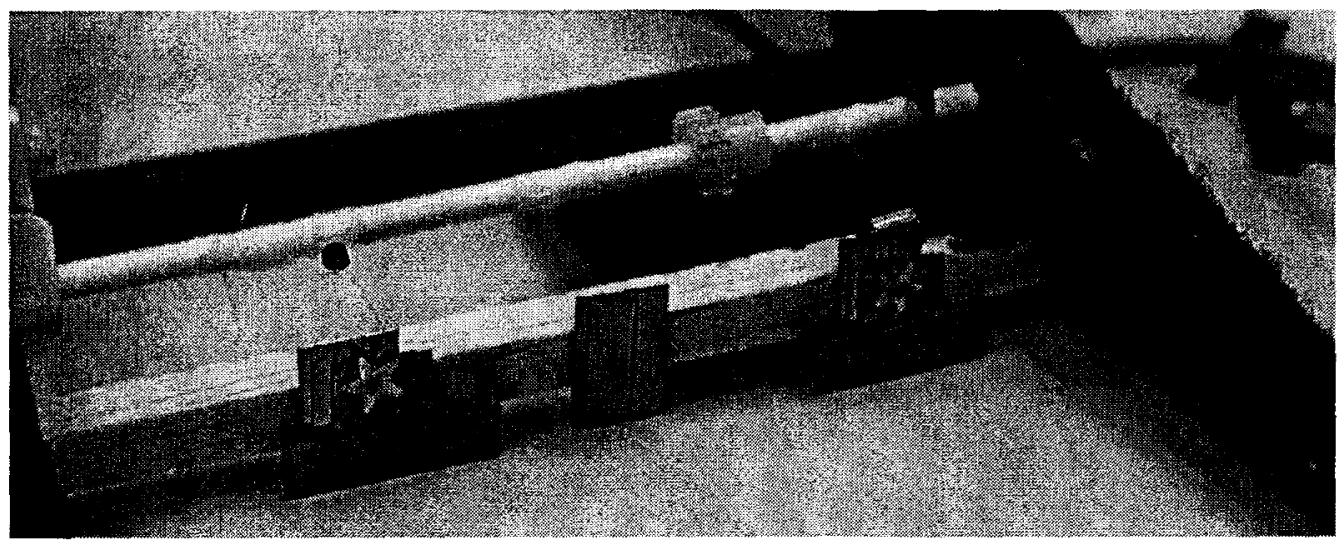

Figure 3.3.9: Pulley method.

Figure 3.3.10 is a close up of a shaft that is connected to the tab by using a hook and rod method. The difference with this method and a previously tested set-up designed by Dr. Nakafuji is that the dovetail track is twice as long as the inserted dovetail with extender tab. A barrier is created at the ends of the dovetail track to prevent the extender tab from coming off of the track. While this method is similar to the pulley method, it is stronger in the sense that the connection between the tab and shaft is sturdier and less likely to snag. The hook and rod system however slightly increases system weight. 


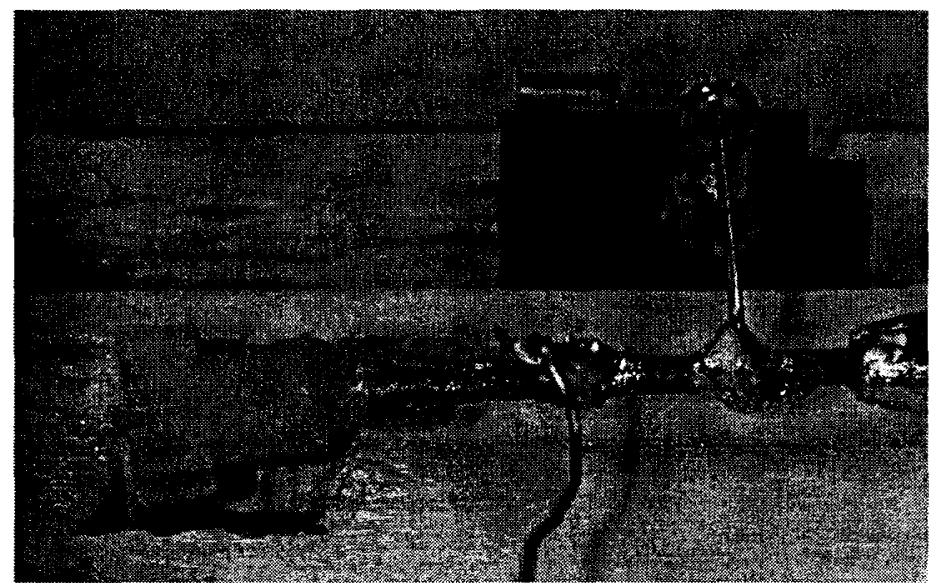

Figure 3.3.10: Hook and rod method.

In summary, each of these methods will be further analyzed. Proof-of-concept models have been developed. Future work includes constructing demonstration models for each method and testing the models under load conditions to further characterize the advantages and disadvantages of each method.

\subsection{SUMMARY \& CONTINUING EFFORTS}

The design attributes resulting from the computational fluid dynamics analysis have allowed the sizing and positioning of the sliding microtab based aerodynamic load control system. These numerical results were paramount to the successful development of this concept and gave us confidence to move forward with the fabrication of the microtabs and the wind-tunnel model. Comparisons of the numerical and the windtunnel results have been made and have verified the effectiveness of the microtab as a load control system for lifting surfaces. The next step in the development is to quantify computationally and experimentally $3-\mathrm{D}$ aerodynamic effects such as gap spacing and gap shaping and to develop a robust tab actuation system.

To achieve future development goals, we plan to 1) characterize microtab flow physics and actuator response for wind-energy applications using numerical simulations and wind tunnel experiments; 2) quantify the response frequency and load changes needed for turbine load mitigation; 3) continue 3-D numerical analysis to gain insight on physics and flow structures generated by the microtabs; 4 ) build experimental platforms to provide guidance for feedback control/logic; and 5) complete acoustic testing and analysis on preliminary microtab geometries.

\section{ACKNOWLEDGEMENTS}

The PIs gratefully acknowledge the help of Dr. William Chan, NASA Ames Research Center, with the overset grid generation process and Professors Rosemary Smith and Scott Collins, University of California at Davis, for use of the microfabrication laboratory and with the design and micro-fab of the tabs and their actuation system. Also we would like to thank Dr. Paul Migliore of NREL for coordinating the acoustic testing effort and Dr. Dale Berg of Sandia National Laboratories for additional financial assistance. Lawrence Livermore National Laboratory (UCRL-JC-150324). 


\section{REFERENCES}

1. Yen, D. T., "Active Load Control using Microtabs", Ph.D. Dissertation, University of California, Davis, 2001.

2. Yen-Nakafuji, D.T., van Dam, C.P., Smith, R.L. and Collins, S.D., "Active Load Control for Airfoils Using Microtabs," Journal of Solar Energy Engineering, Vol. 123, Nov. 2001, pp. 282-289.

3. Zayas, Jose, "UC Davis Wind Tunnel Automation and Airfoil Wake Base Analysis," Report, University of California, Davis, 2002.

4. Hopp, M., "Development and Application of an Automated Wake Analysis Method for Airfoils", Report, University of California, Davis, 2002.

5. Yen, D.T., "Wind Tunnel Pre-Operation Checklist", Report, University of California, Davis, 2000.

6. van Dam, C.P., Yen-Nakafuji, D., Bauer, C., Chao, D. and Standish, K., "Computational Design and Analysis of a Micro-Tab Based Aerodynamic Loads Control System for Lifting Surfaces," SPIE 2003, UCRL-JC-150324.

7. Chan, W.M., "The Overgrid Interface for Computational Simulations on Overset Grids," AIAA Paper 2002-3188, June 2002.

8. Chan, W. M., Rogers, S. E., Nash, S. M., Buning, P. G., and Meakin, R. L., "User's Manual for Chimera Grid Tools, Version 1.6," NASA Ames Research Center, September 2001.

9. Rogers, S. E., and Kwak, D., "An Upwind Differencing Scheme for the Time Accurate Incompressible Navier-Stokes Equations," ALAA Journal, Vol. 28, No. 2, Feb. 1990, pp. 253-262.

10. Rogers, S. E., and Kwak, D., "An Upwind Differencing Scheme for the Steady-state Incompressible Navier-Stokes Equations," Journal of Applied Numerical Mathematics, Vol. 8, No. 1, 1991, pp. 43-64.

11. Chorin, A.J., "A Numerical Method for Solving Incompressible Viscous Flow Problems," Journal of Computational Physics, Vol. 2, 1967, pp. 12-26.

12. Roe, P.L., "Approximate Riemann Solvers, Parameter Vectors, and Difference Scheme," Journal of Computational Physics, Vol. 43, 1981, pp. 357-372.

13. Rogers, S.E., Wiltberger, N.L., and Kwak, D., "Efficient Simulation of Incompressible Viscous Flow over Single and Multielement Airfoils," Journal of Aircraft, Vol. 30, No. 5, Sept.-Oct. 1993, pp. 736-743.

14. Rogers, S.E., "Progress in High-Lift Aerodynamic Calculations," Journal of Aircraft, Vol. 31, No. 6, Nov.-Dec. 1994, pp. 1244-1251.

15. Cao, H.V., and Kusunose, K., "Grid Generation and Navier-Stokes Analysis for Multi-Element Airfoils," AIAA Paper 94-0748, Jan. 1994.

16. Chao, D.D., and van Dam, C.P., "Airfoil Drag Prediction and Decomposition," Journal of Aircraft, Vol. 36, No. 4, July-Aug. 1999, pp. 675-681.

17. Brodeur, R.R., and van Dam, C.P., "Transition Prediction for a Two-Dimensional Navier-Stokes Solver Applied To Wind-Turbine Airfoils," Wind Energy, Vol, 4, 2001, pp. 61-75.

18. Buning, P.G., Jespersen, D.C., Pulliam, T.H., Chan, W.M., Slotnick, J.P., Krist, S.E., and Renze, K.J., "Overflow User's Manual 1.8s," NASA Langley Research Center, November 28, 2000. 
19. Spalart, P.R., and Allmaras, S.R., "A One-Equation Turbulence Model for Aerodynamic Flows," La Recherche Aérospatiale, No. 1, 1994, pp. 5-21.

20. Mayda, E.A., and van Dam, C.P., "Bubble-Induced Unsteadiness on A Wind Turbine Airfoil," Journal of Solar Energy Engineering, Nov. 2002 (in print).

21. Vijgen, P.M.H.W., van Dam, C.P., Holmes, B. J. and Howard, F. G., "Wind Tunnel Investigations Of Wings With Serrated Sharp Trailing Edges," Low Reynolds Number Aerodynamics, Lecture Notes in Engineering, No. 54, T. J. Mueller (Ed.), SpringerVerlag, 1989, pp. 295-313.

22. Van Dam, C.P., Yen, D.T. and Vijgen, P.M.H.W., "Gurney Flap Experiments on Airfoil and Wings," Journal of Aircraft, Vol. 36, No. 2, 1999, pp. 484-486.

23. Bechert, D.W., Meyer, R. and Hage, W., "Drag Reduction of Airfoils with Miniflaps. Can We Learn From Dragonflies?," AIAA Paper 2000-2315, June 2000.

24. Yen, D.T., van Dam, C.P., Braeuchle, F., Smith, R.L. and Collins, S.D., "Active Load Control and Lift Enhancement Using MEM Translational Tabs," Fluids 2000, AIAA Paper 2000-2422, Denver, CO, June 2000.

25. Gonzalez, C., Smith, R.L., Howitt, D.G. and Collins, S.D., "MicroJoinery: Concept, Definition, and Application to Microsystem Development," Sensors and Actuators, A, Vol. 66, 1998, pp. 315-332.

26. Bauer, C., "Microtab Mechanism," Report, University of California, Davis, 2002. 